\title{
Naturally Selected Mate Preferences Appear to Be Androgen-Influenced: Evidence from Two Cultures
}

\author{
Lee Ellis • Malini Ratnasingam
}

Published online: 24 March 2015

(C) Springer International Publishing 2015

\begin{abstract}
An "enhanced" evolutionary theory called evolutionary neuroandrogenic (ENA) theory argues that gender differences in cognitive and behavioral traits result from natural selection favoring gender differences in brain exposure to androgens. This implies that even within males and females, gender dimorphic cognitive and behavioral traits should correlate with androgen exposure. The present study tests this idea regarding mate preferences. Self-reported data were obtained from college students in Malaysia $(N=2058)$ and the USA $(N=2511)$. Twelve traits were assessed in terms of their importance for mate preferences. Ten indicators of androgen exposure were factor-analyzed, resulting in a two-factor solution. The first factor appeared to reflect bone growth and neurosexual influences, while the second factor pertained to muscularity and athletic motor skills. As reported by others, pronounced gender differences were found regarding mate preferences in both countries. Concerning androgenic influences, low scores on bone growth and neurosexual factor were associated with greater mate discrimination tendencies, especially regarding a prospective mate's resource-provisioning capabilities. Preferences for physically attractive mates were positively associated with this factor in the USA but not in Malaysia. The muscularity/athletic factor correlated positively with the assessed importance of nearly all forms of mate preferences for both men and women in both countries. ENA theory correctly predicted associations between androgen exposure and mate preferences, although there appear to be some complex nuances in the nature of androgenic influences on cognitive and behavioral traits. Testing the theory's predictive capabilities with other universal sex differences in behavior is in order.
\end{abstract}

L. Ellis $(\bowtie) \cdot$ M. Ratnasingam

Department of Anthropology and Sociology, University of Malaya, Kuala Lumpur, Malaysia

e-mail: lee.ellis@hotmail.com
Keywords Mate preferences - Gender differences in behavior · Androgens · 2D:4D · Evolution · Neurohormonal influences $\cdot$ Cross-cultural

\section{Introduction}

The time and energy women must devote to producing an offspring greatly exceeds what men must invest. Consequently, women should have been naturally selected for exhibiting greater caution and discrimination in mate selection than would be true for men (Townsend et al. 1995; Trivers 1972). To compensate for their heavy investment, a woman should seek mates who are (or at least seem to be) loyal and capable provisioners of resources through most of her reproductive years (Kokko et al. 2003; Ryan and Rand 1993; Wiley and Poston 1996). Put another way, because females must bear much heavier burdens in order to reproduce, they should have evolved tendencies to be more reserved and discriminating in their mating activities and inclined to prefer devoted mates capable of regularly provisioning resources (Cotton et al. 2006; Edward and Chapman 2011; Ellis 2001; Geary et al. 2004).

Because of men's relatively small investment of time and energy in producing offspring, they should seek to enhance their reproduction by mating with multiple partners to a greater degree than women do (Buss and Schmitt 1993; Gray and Garcia 2013; Kenrick et al. 1990). This means men should be more eager than females to mate, particularly with partners of reproductive age (Marlowe 2004; Sprecher et al. 1994).

\section{Evidence of Gender Differences in Mate Preferences}

The evolutionary reasoning just summarized has received considerable empirical support. Most notably, females 
throughout the world have been shown to be (and to prefer being) more reserved than males in their mating activities (Bradshaw et al. 2010; Kenrick and Trost 1987; Schmitt 2003). Also, compared to males, females are much more prone to bias their preferences toward prospective mates in terms of resource procuring capabilities (Bereczkei et al. 1997; Buss et al. 2001; Greenlees and McGrew 1994; Jennions and Petrie 1997; Moore et al. 2006; Waynforth and Dunbar 1995; Wiederman 1993). Coincidentally, studies of several nonhuman species have found females more readily copulating with males who control the greatest resources or largest/best territories than with other males (Balmford et al. 1992; Ellis 1995; Kirkpatrick and Ryan 1991; Pizzari 2003).

As evolutionary theory predicts, the preferences for mates by males tend to be focused on traits such as youth and physical attractiveness (Kenrick and Keefe 1992; Perusse 1994; Singh 1993), presumably as proxy indicators of fecundity. According to a recent review, nearly all studies have found significantly greater tendencies for males rather than females to consider physical attractiveness an important mate choice criterion (Ellis et al. 2008, pp. 440-441).

\section{Strengths and Weaknesses in Evolutionary Explanations of Behavior}

A lingering criticism of evolutionary explanations of gender differences in behavioral traits has been that the supporting evidence is post hoc (Bell et al. 2001; Boyd 1998). This means that after a particular gender difference is either empirically or anecdotally established, an evolutionary scenario is contrived to fit the observed difference. Consequently, many evolutionary explanations of gender differences in behavior can be considered tantamount to "just-so stories" tailored after the fact to match whatever gender differences seem to exist (Cameron 2010; Cox 2007; Travis 2003).

Proponents of evolutionary explanations for human behavior have countered such criticisms by noting that there are actually numerous ways to identify and cross-check evidence that natural selection forces have been at work on behavioral traits, including sexually dimorphic ones (Confer et al. 2010; Schmitt and Pilcher 2004). These include demonstrating that a behavioral trait (a) appears to be culturally universal, (b) is also common in other species, (c) has neurological and hormonal causes, and (d) seems to be genetically influenced.

We agree that criteria such as those specified above help to identify behavioral traits that have been subjected to past evolutionary pressure. However, we would also point out that the use of these criteria for making judgments about the evolutionary influences on traits is not easily falsified. To illustrate, say that a behavioral trait appears to be unique to humans and exhibits a sex difference in $95-100 \%$ of all societies studied. Can one definitively conclude from such evidence that the trait in question evolved by natural selection? The safest answer would be that such a conclusion is certainly consistent with such an explanation, but it is still somewhat equivocal. Or, say that a sexually dimorphic behavioral trait was shown to be influenced by neurohormonal factors and seems to be genetically influenced as well. With such evidence, can one infer that the trait in question is an evolutionary adaptation?

Most evolutionists would feel comfortable arguing that both of the above questions can be answered affirmatively with a high degree of confidence, but would still have to admit to a skeptic that there is room for doubt. Critics of evolutionary approaches to the study of behavior often seize upon any "room for doubt" as justification for believing otherwise, often opting for social role explanations instead (Eagly and Wood 1999). Therefore, it would be nice to have even more theoretical deductions that could be used to settle the dispute between evolutionary and nonevolutionary arguments regarding human behavior.

The present study was motivated by a belief that Darwinian theory can be strengthened as a scientific explanatory system as it was a century ago with what came to be known as the modern synthesis (Huxley 1942; Mayr 1998; Rose and Oakley 2007). In the modern synthesis, knowledge of genetics was interwoven with Darwin's concept of natural selection. This synthesis made Darwin's original formulation stronger and more comprehensive by wedding the concept of natural selection with information about the biochemistry behind the traits being selected. In the theory to be described, we believe that Darwinian explanations can be made stronger for one important class of traits, i.e., those having to do with gender differences.

\section{An Enhanced Evolutionary Theory of Gender Differences}

We believe that another synthesis involving evolutionary theory is possible. It essentially argues that some of the genes that have evolved are responsible for sexual differentiation, and these genes operate in large measure by causing males and females to produce different hormone regimens. These hormone regimens, in turn, produce average sex differences in many cognitive and behavioral patterns, nearly all of which are subjected to natural selection.

This theoretical enhancement should be useful for better understanding sex difference in behavior, especially ones that are virtually universal in the human species. While evolutionary theory covers many questions besides those involving sex differences in behavior, these differences are central to disciplines such as evolutionary psychology and sociobiology (Buss 1995; Daly and Wilson 1999; Geary 2010; Low 2001) and may be at the very the heart of social science itself (Ellis et al. 2008; Mealey 2000). As simply stated by Udry (1994, p. 561), "human nature is gendered".

The enhanced Darwinian theory to be utilized here retains the concept of natural selection as well as the growing understanding of how genes orchestrate the continuation of life as 
depicted in the modern synthesis. What is new to the enhanced theory is that it incorporates information derived in the past half century or so regarding (a) the role of sex hormones in altering brain functioning and (b) the impact that these neurohormonal factors have on behavior (for summaries, see BaronCohen et al. 2005; Cahill 2006; Collaer and Hines 1995; Geary 2010; Kimura 1992).

The name given to this enhanced theory is evolutionary neuroandrogenic (ENA) theory (Ellis 2011a, b). It asserts that combinations of genes have evolved that code for sex hormone regimens that effectively drive male and female apart in terms of numerous average cognitive and behavioral traits. In this way, according to the theory, members of both genders are more successful in passing genes onto future generations than would be the case without these sexually differentiated hormones. Boiled down even further, ENA theory asserts that sex hormones have evolved to produce numerous sex differences in behavior.

The main advantage of ENA theory over conventional evolutionary theory is that it specifies how, rather than simply why, sex differences in many types of behavior have arisen. Because it inextricably links arguments about evolution with complimentary arguments of a neurohormonal nature, ENA theory is much more open to direct empirical refutation than Darwinian theory has been even after the modern synthesis.

Two core premises are at the heart of ENA theory. The first is as follows: To the extent that gender differences in behavior are present in all established human cultures (which is extensive-Ellis 2011a), these differences have been naturally (including sexually) selected (either directly or indirectly). Sex differences that are indirectly selected would be those that are not promoting reproduction themselves, but are "side effects" of traits that $d o$ promote reproduction for one or both sexes.

A likely example of indirect selection involves the condition of autism, which is at least five or six times more common among males than females (review: Ellis et al. 2008, p. 405). No one would seriously argue that male preponderance in autism has been directly favored by natural selection. However, the sex difference could be explained as being a side effect of selection for male traits that have helped males attract mates. In this regard, at least one study has found autism to be unusually common among boys whose fathers (and even grandfathers) were mathematicians and engineers (Baron-Cohen et al. 1997). Such a familial connection between involvement in STEM occupations (i.e., those involving science, technology, engineering, and mathematics) and autism can be explained in evolutionary terms as follows:

1. Males who gravitate toward STEM occupations are likely to be unusually attractive as mates to females intending to have offspring since males in these occupations are likely to earn stable comfortable incomes more than males in general (Langdon et al. 2011; Lubinski and Benbow 2006).
2. Genetics throughout the genome appears to contribute considerably to the tendencies to have STEM interests and abilities (Gottfredson 2003; Simonton 2008; Toga and Thompson 2005).

3. These STEM-promoting genes appear to interact with genes affecting brain exposure to testosterone (primarily located on the $\mathrm{Y}$ chromosome), thereby virtually assuring that males will be more STEM-oriented than females (Benbow 1988; Berenbaum and Beltz 2011).

4. However, the very genes that contribute to STEM interests and abilities also appear to increase the probability of autistic tendencies, such as focusing on detailed physical movements and reduced interest in language and interpersonal interactions (Baron-Cohen 2008).

5. Consequently, the very factors that have helped nudge males toward STEM occupations (thereby making them attractive to females as long-term mates) may have side effects that elevate the risk of autism, with high prenatal exposure to testosterone playing a central role (Baron-Cohen et al. 1997, 2005).

These arguments need more verification than presented here, but they serve to illustrate the idea that sexually dimorphic traits can be indirectly selected as well as directly selected (for other possible examples, see Keller and Miller 2006).

The second core premise of ENA theory is that all naturally (including sexually) selected gender differences are primarily the result of differential exposure of the brain to androgens, either perinatally, postpubertally, or both. Put another way, (a) brain exposure to androgens is responsible for all culturally universal male-typical cognitive and behavioral traits, while (b) the absence of brain exposure to androgens (or its metabolites) increases all universal female-typical traits.

This second premise makes ENA theory very falsifiable. All one needs to do to negate the theory is to locate a universal sex difference in cognition or behavior that is not the result of androgenic effects on brain functioning. Thus, to the extent the theory is true, brain exposure to androgens must be responsible for the evolution of all universal gender differences in behavior. If so, correlations should be found between universal gender differences in cognition and behavior and androgen levels even if males and females are examined separately.

Nearly all contemporary Darwinian scholars are aware of the major advances that have been made in understanding how androgens contribute to sexual differentiation, and many of them incorporate neuroandrogenic concepts into their explanations of sex differences in behavior (e.g., Daly and Wilson 1978; Demski 1984; Crews and Moore 1986; Geary 2010; Sinervo et al. 2000). However, ENA theory does more than recognize that evolutionary and neurohormonal variables are interrelated. It specifies the nature of these relationships in ways that can be empirically tested. 
Hypothesis

The present study provides a set of tests for ENA theory regarding gender differences in traits that prior studies have suggested are universal, or nearly so, with respect to mate preferences (Buss and Schmitt 1993; Ellis et al. 2008; Shackelford et al. 2005). Five hypotheses were derived from the theory. The first three hypotheses emanated from ENA theory's evolutionary component, while the latter two were derived from its neurohormonal component:

$\mathrm{H}_{1}$ Because females risk losing more in reproductive terms from the mate choices they make, they should be more discriminating in their mate preferences than males. $\mathrm{H}_{2}$ Female mate preferences should be especially strong regarding traits indicative of loyalty and an ability to provide resources throughout the duration of a couple's reproductive years.

$\mathrm{H}_{3}$ Male mate preferences should focus on choosing mates with relatively high reproductive potential (i.e., those who are physically attractive and healthy).

$\mathrm{H}_{4}$ Regarding neurohormonal factors, androgen exposure should be inversely associated with strong preferences for most mate choice criteria, especially those involving loyalty and resource procurement capabilities.

$\mathrm{H}_{5}$ Brain exposure to androgens should be positively associated with preferences for mates who are physically attractive and healthy.

Two notable qualifications need to be made regarding the latter two hypotheses. One is that ENA theory predicts that the relationships stipulated should exist even after controlling for gender. In other words, not only should males and females differ in terms of their average degree of exposure to perinatal androgens and thereby their preferences for mates but even within each gender, the correlations stated in $\mathrm{H}_{4}$ and $\mathrm{H}_{5}$ should still be present.

The second qualification is that ENA theory asserts that it is primarily perinatal exposure to androgens that imposes most of the permanent sexual differentiation onto the brain (Ellis 2011b). Therefore, postpubertal exposure to androgens is expected to primarily only enhance the expression of whatever neurological predispositions were laid down during perinatal brain development (Evuarherhe et al. 2009; Schulz et al. 2009). Therefore, it is likely that the strongest correlations between mate preference patterns and androgens would involve the exposure received prenatally rather than after puberty.

\section{Methods}

The present study's respondents consisted of undergraduate college students in Malaysia and the USA. Specifically,
2059 Malaysian students attending the University of Malaya completed a questionnaire. In the USA, students from the following eight universities also completed a questionnaire: Boise State University (145 respondents), California State University at Fullerton (251 respondents), Evangel University (264 respondents), Minot State University (173 respondents), Pennsylvania State University (110 respondents), the University of Missouri (258 respondents), University of Texas at the Permian Basin (1048 respondents), and the University of Texas at San Antonio (261 respondents), for a total of 2511 US respondents.

\section{Demographics}

Demographics for the two countries' respondents are shown in Table 1. Regarding gender, substantially more females were sampled than males largely due to more females attending college in both countries in recent years (DiPrete and Buchmann 2006; Firebaugh and Dorius 2010).

The questionnaire was developed and refined in English and then translated into Bahasa Malaysia, Malaysia's official national/native language. To help ensure that the translation was equivalent to the English version, the Malaysian questionnaire was back-translated into English until all discrepancies were eliminated. (However, as will be discussed below, one failure in equivalency was detected after all data from Malaysia had been collected). Both questionnaires were four pages in length and covered a wide variety of topics, only some of which are part of the present study.

\section{The Mate Preference Measures}

To assess the importance of various criteria used in mate choices, respondents were given the following instructions followed by the listing of 12 traits: Besides mutual love, rate the following traits regarding what you would be looking for in a marriage partner (or did look for if you are already married). Rate your responses with $\mathbf{0}$ meaning not at all important and 10 meaning indispensable.

Good financial prospects

Compatible personality

Emotional stability (rarely gets angry)

Having similar religious views

Intelligence and education

Sense of humor

Compatible family background

Chastity (fidelity)

Desire for a home and children

Ambition and industriousness

Physical attractiveness (good looks)

Good mental and physical health 
Table 1 Demographic composition of the samples

\begin{tabular}{|c|c|c|}
\hline Demographic traits & Malaysian sample & US sample \\
\hline \multicolumn{3}{|l|}{ Gender } \\
\hline Males & $652(31.7 \%)$ & $1027(49.9 \%)$ \\
\hline Females & $1406(68.3 \%)$ & $1485(50.1 \%)$ \\
\hline Total & 2058 & 2511 \\
\hline \multicolumn{3}{|l|}{ Age } \\
\hline Mean (standard deviation) & $20.86(2.36)$ & $23.96(9.27)$ \\
\hline Range & $18-42$ & $17-81$ \\
\hline Total & 2058 & 2511 \\
\hline \multicolumn{3}{|l|}{ Marital status } \\
\hline Single (including engaged, domestic partners) & $1971(95.7 \%)$ & $2009(80.0 \%)$ \\
\hline Married & $37(1.8 \%)$ & $341(13.6 \%)$ \\
\hline Divorced/separated & $1(0.0 \%)$ & $77(3.1 \%)$ \\
\hline No response or other & $50(2.4 \%)$ & $46(1.8 \%)$ \\
\hline Total & 2058 & 2511 \\
\hline \multicolumn{3}{|l|}{ Ethnicity } \\
\hline White/European ancestry & 0 & $1394(55.5 \%)$ \\
\hline Black/African ancestry & 0 & $173(6.9)$ \\
\hline Hispanic/Latin/Native American & 0 & $745(29.8 \%)$ \\
\hline Malay/Bumiputera/Indonesian & $1474(7164 \%)$ & $5(0.2 \%)$ \\
\hline East Asian (Chinese, "Asian" in the USA) & $477(23.2 \%)$ & $66(2.6 \%)$ \\
\hline Other Asian (primarily Indian) & $85(4.1 \%)$ & $51(2.2 \%)$ \\
\hline Other (mixed, Arabic, Persian, Euro-Asian) & $3(0.1 \%)$ & $64(2.5 \%)$ \\
\hline No response & $19(0.9 \%)$ & $13(0.1 \%)$ \\
\hline Total & 2058 & 2511 \\
\hline
\end{tabular}

The Androgen Influence Measures

ENA theory specifies that it is the effects of androgens on brain functioning that are responsible for any widespread gender differences in preferences and behavior. However, the only direct measure of brain exposure to androgens would involve spinal taps, an obviously painful and risky procedure that no one would perform simply for research purposes. In the present study, brain exposure to androgens was inferred by combining ten physical traits that are known to be androgen-influenced, all based on each respondent's self-assessments. As elaborated on below, these traits were the 2D:4D finger length ratio, muscularity, physical strength, low deep voice (voice timbre), height, athletic ability, masculine body appearance, feminine body appearance, masculine mannerisms, and feminine mannerisms.

\section{The 2D:4D Measurement}

Numerous studies have indicated that the relative length of the second and the fourth fingers can be considered a biomarker for prenatal exposure to testosterone, in humans (Manning et al. 1998, 2013) along with other mammals (McFadden and Bracht 2005; Zheng and Cohn 2011). The evidence includes a study in which rat fetuses were experimentally injected with testosterone and shown to exhibit altered digit lengths as a result (Talarovičová et al. 2009).

In humans, while objective physical measurement of this $2 D: 4 D$ ratio is more accurate than self-assessment based on mere visual examination (Hönekopp and Watson 2010), even self-reports appear to provide a modestly reliable method for estimating the ratio when large numbers of respondents are sampled (Manning et al. 2007a).

The only 2D:4D ratio assessed in the present study was for the right hand, henceforth referred to as the $r 2 D: 4 D$ ratio. This was done in light of several studies having concluded that the right hand provides a more reliable measure of prenatal androgen exposure than does the 2D:4D ratio for the left hand (Brown et al. 2002; Grimbos et al. 2010; Kastlunger et al. 2010; Manning et al. 2005, 2007a, b; Williams et al. 2000; for an exception, see Putz et al. 2004).

Similar to Manning et al. (2007a, b), our r2D:4D measure was based on responses to the following question: Hold up the back of your right hand so that you can see all five fingers. With your thumb as the first finger, compare the lengths of your 2nd (pointing) finger with your 4th (ring) finger. Which is longer? (check one of the five responses below) 
Index (pointing) finger considerably longer

Index (pointing) finger slightly longer

They are almost exactly the same length

Ring (fourth) finger slightly longer

Ring (fourth) finger considerably longer

Research has indicated that the longer the ring finger (4D) relative to the pointing finger (2D), the greater the exposure to prenatal testosterone (and possibly other androgens) (Voracek et al. 2007). Thus, the above five responses were coded from 5 to 1 , thus rendering a measure of the $\mathrm{r} 2 \mathrm{D}: 4 \mathrm{D}$ ratio comparable to earlier studies associating low ratios with high androgen exposure.

To check the reliability of the self-reported r2D:4D measure, near the end of our data collection, we provided a subsample of 454 of the US respondents with a sheet of paper as a special attachment to their questionnaires. These respondents were asked to carefully trace an outline of their right hand. The lengths of the second and fourth fingers of these tracings were physically measured in millimeters by trained observers, which allowed us to then calculate the r2D:4D ratios for these two fingers. The drawing-based measures were then correlated with the self-estimates provided by the 454 respondents. The correlation was $r=0.214$, highly significant statistically, but obviously rather low from a reliability standpoint. Based on this result and the prior literature on 2D:4D, we assume that neither measure can be considered much more than generally indicative of prenatal androgen exposure.

\section{Other Androgen-Influenced Traits}

Nine additional androgen-influenced traits were measured. These were physical strength, muscularity, low deep voice (voice timbre), height, athletic ability, masculine and feminine body appearances, and masculine and feminine mannerisms.

Height was measured by asking each respondent to report his or her current height. In Malaysia, respondents reported their heights in centimeters, while the US students did so in terms of feet and inches (which were converted into centimeters). To obtain the remaining eight measures, respondents were asked the following questions: Being as objective as possible, rate yourself on the following traits (0 meaning "not at all" to 10 meaning "the most extreme degree possible”).

Physical strength
Being muscular
Having a low deep voice
Athletic ability
Masculine body appearance
Masculine mannerisms
Feminine body appearance
Feminine mannerisms

From the standpoint of accuracy, there is no doubt that it would have been preferable to have obtained measurement of the above traits by trained researchers using various precision instruments. However, to save time, expense, and to be able to assure anonymity to the respondents, this study relied entirely on self-assessments.

Despite the efforts made to ensure that the wording for the Malaysian version of the questionnaire was equivalent to that of the English version, one inconsistency was detected after all of the data had been collected. This inconsistency involved the item pertaining to low deep voice. The specific wording for this particular question in the Malaysian language was "Mempunyai suara yang bernada rendah" and the literal back-translation for this phrase was having a voice with low tone. However, this translation appears to have been misinterpreted by many of the Malaysian respondents as meaning a soft quiet voice rather than the intended meaning of a low deep voice. As a result, Table 2 shows that no significant gender differences in the Malaysians' responses were found for this item. Nevertheless, we are confident that Malaysian males have significantly lower and deeper voices than do females, just as is true elsewhere in human populations (Evans et al. 2006; Lee et al. 1999; Puts et al. 2012).

\section{Factor Analysis of the Androgen-Influenced Traits}

To condense the measures of androgen-influenced traits, we subjected both the Malaysian and the US samples to separate factor analyses. Using orthogonal rotation, two factors emerged for both samples with eigenvalues surpassing 1.00. The loadings for each of the ten traits (nine in the case of Malaysia) on these two factors are shown in Table 3. One can see that their loadings were very similar.

For both countries, six traits loaded most heavily onto factor 1 . These were r2D:4D, height, masculine mannerisms, masculine body appearance, feminine body appearance, and feminine mannerisms. Regarding the US sample, voice timbre also loaded most onto factor 1 (while it was excluded from the analysis for the Malaysian sample for reasons already explained).

It should be noted that the $2 \mathrm{D}: 4 \mathrm{D}$ ratio variable loaded rather weakly onto factor 1 in both countries, although its sign was as expected (i.e., negative, the same as for feminine body appearance and feminine mannerisms). Most researchers have concluded that 2D:4D is a low to modest biomarker of prenatal exposure to testosterone androgens (Breedlove 2010; Hönekopp et al. 2006; Manning 2011; Manning et al. 1998; McIntyre 2006; Putz et al. 2004; van Anders et al. 2006; Voracek et al. 2007), although others have suggested that 2D:4D is not valid at least for inferring individual level exposure to prenatal androgens (Berenbaum et al. 2009; Medland et al. 2010). A view close to our own was offered by Hell and Paßler (2011, p. 379) in which they described 2D:4D as "a 
Table 2 Sex differences in the eight androgen-influenced traits according to country

\begin{tabular}{|c|c|c|c|c|c|c|c|}
\hline \multirow[t]{2}{*}{ Traits } & \multirow[t]{2}{*}{ Country } & \multicolumn{2}{|l|}{ Males } & \multicolumn{2}{|l|}{ Females } & \multirow[t]{2}{*}{$t$} & \multirow[t]{2}{*}{$p$} \\
\hline & & Mean & SD & Mean & SD & & \\
\hline \multirow[t]{2}{*}{ r2D:4D, self-reported } & Malaysia & 2.58 & 1.07 & 2.86 & 1.11 & -5.266 & 0.000 \\
\hline & USA & 2.25 & 0.91 & 2.65 & 1.01 & -9.215 & 0.000 \\
\hline \multirow[t]{2}{*}{ Physical strength } & Malaysia & 6.73 & 2.27 & 6.45 & 2.26 & 2.638 & 0.008 \\
\hline & USA & 6.65 & 2.17 & 5.61 & 2.30 & 11.376 & 0.000 \\
\hline \multirow[t]{2}{*}{ Muscularity } & Malaysia & 4.75 & 2.53 & 2.64 & 2.55 & 17.485 & 0.000 \\
\hline & USA & 5.65 & 2.45 & 3.79 & 2.57 & 18.031 & 0.000 \\
\hline \multirow[t]{2}{*}{ Low deep voice } & Malaysia $^{a}$ & 4.84 & 2.90 & 4.80 & 2.92 & 0.303 & 0.762 \\
\hline & USA & 5.74 & 2.68 & 1.79 & 2.58 & 36.481 & 0.000 \\
\hline \multirow[t]{2}{*}{ Height } & Malaysia & 169.77 & 6.99 & 158.23 & 6.11 & 35.065 & 0.000 \\
\hline & USA & 180.71 & 12.60 & 168.43 & 13.49 & 22.926 & 0.000 \\
\hline \multirow[t]{2}{*}{ Athletic ability } & Malaysia & 5.03 & 2.75 & 3.59 & 2.70 & 11.070 & 0.000 \\
\hline & USA & 6.63 & 2.60 & 5.02 & 2.95 & 14.263 & 0.000 \\
\hline \multirow[t]{2}{*}{ Masculine body appearance } & Malaysia & 8.00 & 2.37 & 0.96 & 1.92 & 65.445 & 0.000 \\
\hline & USA & 6.60 & 2.98 & 1.79 & 2.76 & 40.386 & 0.000 \\
\hline \multirow[t]{2}{*}{ Masculine mannerisms } & Malaysia & 8.53 & 2.05 & 2.32 & 2.66 & 57.367 & 0.000 \\
\hline & USA & 6.90 & 2.93 & 2.58 & 2.93 & 35.738 & 0.000 \\
\hline \multirow[t]{2}{*}{ Feminine body appearance } & Malaysia & 1.11 & 2.40 & 7.76 & 2.48 & -57.388 & 0.000 \\
\hline & USA & 2.01 & 3.24 & 7.49 & 2.92 & -42.806 & 0.000 \\
\hline \multirow[t]{2}{*}{ Feminine mannerisms } & Malaysia & 1.30 & 2.43 & 7.60 & 2.41 & -54.786 & 0.000 \\
\hline & USA & 2.20 & 3.02 & 7.42 & 2.72 & -43.624 & 0.000 \\
\hline
\end{tabular}

${ }^{\text {a }}$ See the "Methods" section for an explanation for why low deep voice for the Malaysian sample failed to reflect a significant gender difference

very 'noisy' indicator" of prenatal androgen exposure. In other words, as an indicator of prenatal androgen exposure, 2D:4D measurement appears to contain a great deal of random error, but with sufficiently large samples, it can still be considered a valid indicator at a group level.

While recognizing its limited precision, we believe that 2D:4D measurement, even when simply self-reported, is useful for inferring group differences in perinatal androgen exposure provided large samples are utilized (Manning and Fink 2008). Furthermore, when our r2D:4D measure was part of a factor analysis of nine other androgen-influenced traits, Table 3 shows that two androgen factors emerge and that 2D:4D is modestly associated only with the first of these two factors.

In naming the factors, we were guided by the assumption that whatever factor r2D:4D was most heavily loaded upon was almost certainly mainly tapping into prenatal testosterone exposure. Also, we assumed that the emerging factors should be similar for both countries sampled. Nevertheless, the precise names given to these factors are explained below.

Factor 1 The Bone Growth and Neurosexing (BGNS) Factor. The reasons for naming factor 1 the BGNS factor were as follows: First, the traits that factor 1 loaded most heavily upon were those involving height and sexually dimorphic appearance and mannerisms.

Second, studies suggest that substantial sex differences in finger length ratios are already present at birth and even before (Galis et al. 2010). Nevertheless, male-female differences in 2D:4D continue to diverge slightly more throughout childhood and even adolescence (Galis et al. 2010; Trivers et al. 2006). Table 3 reveals that while r2D:4D did not load heavily onto either factor (especially for the Malaysian sample), its best loadings by far were on factor 1 . This presumably reflects the considerable random error associated with the present selfreport measure of $\mathrm{r} 2 \mathrm{D}: 4 \mathrm{D}$ added to the fact that even the most precise r2D:4D measure is at best only a rough indicator of prenatal androgen exposure (Berenbaum et al. 2009; Hell and Paßler 2011; Medland et al. 2010).

Factor 2 The Muscularity and Gross Motor Coordination (MGMC) Factor. Table 3 indicates that for both the Malaysian and the US samples, factor 2 is comprised of high loadings (well over 0.50 ) for the same three traits: physical strength, muscularity, and athletic ability. Sex differences in muscularity and coordination are fairly minor throughout childhood (Malina 1978; Neu et al. 2002), but major sex 
Table 3 Factor loadings for the ten self-assessed androgen-influenced traits using principle extraction method with orthogonal rotation (The three italicized variables were expected to be in the opposite direction relative to the remaining seven variables. The variable loadings that were the highest for each factor are in bold)

\begin{tabular}{|c|c|c|c|c|}
\hline \multirow[t]{2}{*}{ Self-rated traits } & \multicolumn{2}{|c|}{ Rotated factor loadings, Malaysia } & \multicolumn{2}{|c|}{ Rotated factor loadings, USA } \\
\hline & $\begin{array}{l}\text { Factor 1: bone growth } \\
\text { and neurosexing }\end{array}$ & $\begin{array}{l}\text { Factor 2: muscularity and } \\
\text { gross motor coordination }\end{array}$ & $\begin{array}{l}\text { Factor 1: bone growth } \\
\text { and neurosexing }\end{array}$ & $\begin{array}{l}\text { Factor 2: muscularity and } \\
\text { gross motor coordination }\end{array}$ \\
\hline$r 2 D: 4 D$ & -0.116 & -0.063 & -0.326 & 0.018 \\
\hline Physical strength & -0.103 & 0.769 & 0.085 & 0.835 \\
\hline Muscularity & 0.333 & 0.743 & 0.226 & 0.851 \\
\hline Low deep voice & Omitted $^{\mathrm{a}}$ & Omitted $^{\mathrm{a}}$ & 0.732 & 0.244 \\
\hline Height & 0.687 & 0.147 & 0.416 & -0.090 \\
\hline Athletic ability & 0.185 & 0.768 & 0.119 & 0.811 \\
\hline Masculine mannerisms & 0.865 & 0.224 & 0.822 & 0.256 \\
\hline Masculine body appearance & 0.880 & 0.262 & 0.829 & 0.334 \\
\hline Feminine mannerisms & -0.932 & 0.026 & -0.873 & -0.122 \\
\hline Feminine body appearance & -0.922 & 0.055 & -0.895 & -0.071 \\
\hline Eigenvalues & 4.143 & 1.619 & 3.997 & 1.631 \\
\hline
\end{tabular}

"As explained in the "Methods" section, low deep voice was excluded from the factor analysis for the Malaysian sample because of poor phrasing of the item used to measure this variable when it was translated from English to Bahasa Malaysia

differences manifest themselves following puberty (Buyken et al. 2009; Loos et al. 1997; Thomas and French 1985). Sex differences in these three traits are largely unexpressed until the onset of puberty in response to the postpubertal surge in testosterone (Bhasin et al. 1996; Van Praagh et al. 1990; Woodhouse et al. 2003). At puberty, androgen levels surge especially for males, thereby producing major sex differences in muscularity and gross motor coordination (Inglis et al. 2013; Temfemo et al. 2009).

While exposure to high postpubertal androgens promotes both bone growth and muscular growth, the two forms of growth are still largely independent events, especially within the sexes (Daly et al. 2004). Furthermore, twin studies indicate that separate autosomal genes control these two growth processes (Seeman et al. 1996). For these reasons, it is not surprising that a bone growth factor (factor 1 ) and a muscle growth factor (factor 2) were statistically distinguished.

While both factor 1 and factor 2 are derived from the influence of prenatal androgens, Table 3 suggests that this is truer for factor 1 . Nevertheless, experiments with rats have shown that exposing muscle tissue to high (male-typical) levels of prenatal androgens is a necessary precursor for the activating pubertal surge in androgens to be maximally effective in strengthening the muscles following the onset of puberty (Breedlove and
Hampson 2002). In this regard, a recent study reported that $\mathrm{r} 2 \mathrm{D}: 4 \mathrm{D}$ is inversely correlated with physical strength even within males (Fink et al. 2006). Also, at least three studies have shown that 2D:4D is inversely associated with athletic ability (Hönekopp and Schuster 2010; Manning et al. 2007b; Voracek et al. 2007). Consequently, it is surprising to find almost no loading of our r2D:4D measure onto factor 2.

Overall, at the heart of factor 2 are the traits of physical strength, muscularity, and athletic ability, all of which loaded above 0.70 for the Malaysian sample and over 0.80 for the US sample. Therefore, we named it the MGMC factor. Factor 1, on the other hand, had more to do with bone growth and sexual differentiation of appearance and mannerisms; thus, it was named the BGNS factor.

Data Analyses

$t$ tests were used to compare gender differences in all eight androgen exposure variables along with all 12 of the mate preference variables. Factor analysis was employed to determine the underlying factor structure of the eight androgeninfluenced traits. The resulting two factors were then correlated with the 12 mate preference variables using Pearson correlation and then using partial correlation in order to control for gender. 


\section{Results}

Each of the five hypotheses are given separate attention in numerical order.

$\mathrm{H}_{1}$ Gender Differences in Discriminatory Mate Preferences

According to ENA theory, females should be more discriminating than males in choosing mates. This prediction follows from the fact that females cannot escape devoting more time and energy to successfully producing an offspring, a fact that will favor females exercising greater caution and discrimination in choosing mates than is true for males.

Table 4 presents evidence bearing on this prediction. It shows the average ratings given by males and females in both countries and $t$ score measures of the extent to which the average ratings differ according to gender. Consistent with $\mathrm{H}_{1}$, females in both countries rated many more of the 12 criteria for mate preferences higher than did males. Out of the 24 comparisons (12 for each country), only four exceptions were found. They were as follows:

1. Among the Malaysians, females expressed a stronger desire for an emotionally stable mate than did males, although the difference fell slightly short of statistical significance.

2. No significant difference between Malaysian males and females was present regarding their desires for a mate who wanted to share a home and family.

3. For Malaysians, there was no significant gender difference in ratings of the importance of physical attractiveness as a mate selection criterion.

4. In the US sample, males and females did not differ regarding the importance they gave to their mates having good mental and physical health.

Overall, in Malaysia, females rated 9 of the 12 traits as significantly more important for choosing mates than did males. In the USA, 11 of the 12 traits were considered significantly more important by females than by males. Putting results for the two countries together, the

Table 4 Sex differences in the 12 mate preference criteria according to country

\begin{tabular}{|c|c|c|c|c|c|c|c|}
\hline \multirow[t]{2}{*}{ Traits } & \multirow[t]{2}{*}{ Country } & \multicolumn{2}{|l|}{ Males } & \multicolumn{2}{|c|}{ Females } & \multirow[t]{2}{*}{$t$} & \multirow[t]{2}{*}{$p$} \\
\hline & & Mean & SD & Mean & $\mathrm{SD}$ & & \\
\hline \multirow[t]{2}{*}{ Good financial prospects } & Malaysia & 6.95 & 2.70 & 7.97 & 1.98 & -7.97 & 0.000 \\
\hline & USA & 6.50 & 2.59 & 7.25 & 2.25 & -6.98 & 0.000 \\
\hline \multirow[t]{2}{*}{ Personality compatibility } & Malaysia & 7.89 & 2.26 & 8.16 & 1.91 & -2.45 & 0.014 \\
\hline & USA & 8.66 & 1.74 & 8.86 & 1.58 & -2.69 & 0.007 \\
\hline \multirow[t]{2}{*}{ Emotional stability } & Malaysia & 7.94 & 1.99 & 8.13 & 1.98 & -1.79 & 0.074 \\
\hline & USA & 7.75 & 2.03 & 8.20 & 3.08 & -4.09 & 0.000 \\
\hline \multirow[t]{2}{*}{ Having similar religious views } & Malaysia & 7.92 & 2.55 & 8.24 & 2.39 & -2.53 & 0.012 \\
\hline & USA & 5.90 & 3.54 & 6.97 & 4.23 & -6.42 & 0.000 \\
\hline \multirow[t]{2}{*}{ Intelligence and education } & Malaysia & 7.38 & 2.25 & 7.90 & 2.00 & -4.67 & 0.000 \\
\hline & USA & 7.79 & 1.94 & 8.27 & 2.67 & -4.85 & 0.000 \\
\hline \multirow[t]{2}{*}{ Sense of humor } & Malaysia & 7.50 & 2.25 & 7.96 & 2.04 & -3.97 & 0.000 \\
\hline & USA & 8.69 & 1.62 & 8.84 & 1.58 & -2.13 & 0.033 \\
\hline \multirow[t]{2}{*}{ Compatible family background } & Malaysia & 6.92 & 2.69 & 7.38 & 2.42 & -3.41 & 0.001 \\
\hline & USA & 5.92 & 3.10 & 6.57 & 2.84 & -4.98 & 0.000 \\
\hline \multirow[t]{2}{*}{ Chastity (fidelity) } & Malaysia & 8.78 & 1.98 & 9.09 & 1.69 & -3.15 & 0.002 \\
\hline & USA & 6.73 & 3.26 & 7.87 & 2.96 & -8.36 & 0.000 \\
\hline \multirow[t]{2}{*}{ Desire for a home and children } & Malaysia & 8.44 & 2.29 & 8.52 & 2.16 & -0.73 & 0.467 \\
\hline & USA & 7.87 & 2.49 & 8.40 & 2.28 & -5.45 & 0.000 \\
\hline \multirow[t]{2}{*}{ Ambition and industriousness } & Malaysia & 8.34 & 2.02 & 8.82 & 1.75 & -4.86 & 0.000 \\
\hline & USA & 7.75 & 2.09 & 8.46 & 2.27 & -7.44 & 0.000 \\
\hline \multirow[t]{2}{*}{ Physical attractiveness (good looks) } & Malaysia & 7.61 & 2.31 & 7.54 & 2.11 & 0.64 & 0.524 \\
\hline & USA & 8.11 & 3.48 & 7.26 & 1.98 & 6.71 & 0.000 \\
\hline \multirow[t]{2}{*}{ Good mental and physical health } & Malaysia & 8.38 & 2.01 & 8.61 & 1.85 & -2.33 & 0.020 \\
\hline & USA & 8.56 & 1.63 & 8.47 & 1.55 & 1.34 & 0.182 \\
\hline
\end{tabular}


proportional gender differences were statistically significant: $\chi^{2}=9.375, d f=1, p=0.002$ (Yates adjusted).

$\mathrm{H}_{2}$ Female Bias Toward Loyalty and Resource Procurement Capabilities

ENA theory predicts that females should be inclined to focus on traits of prospective mates indicative of loyalty and the ability to procure resources to a greater extent than do males. Table 4 provides evidence pertaining to this prediction. It reveals a modest degree of support for the hypothesis when one examines the strength of the $t$ scores. For the Malaysian students, the two strongest gender differences involved good financial prospects and ambition and industriousness. Predictably, females rated both of these traits as being significantly more important than did the males. Other noteworthy traits that females in Malaysia rated significantly higher than did males were personality compatibility and chastity. One could argue that this would be so given that they both are indicators of long-term loyalty.

In the US sample, the trait for which the greatest gender difference was found with females providing the highest ratings was chastity. Theoretically, this could be reflecting the tendency for females to emphasize loyalty among the mates they choose. The next two greatest gender differences, again favored females, went to the traits of ambition and industriousness and good financial prospects, which one can assume to be indicators of being good resource provisioners. The fourth greatest gender difference among the US sample involved physical attractiveness, the only trait that was significantly different with male ratings being higher that the ratings by females.

Also worth noting in connection with a mate's ability to effectively provision is that females in both countries rated intelligence and education as being significantly more important than males did as a mate choice criterion. Overall, Table 4 provides general support for $\mathrm{H}_{2}$ in both Malaysian and the US samples. The main exception is that no significant gender difference was found in the Malaysian sample regarding the importance of physical attractiveness as a mate choice criterion.

$\mathrm{H}_{3}$ Male Bias Toward High Reproductive Potential

ENA theory leads one to hypothesize that to the extent males are favored for being choosey in mate selection, their focus should be primarily on indicators of high reproductive potential. The two most obvious indicators of reproductive potential utilized in the present study were those of physical attractiveness and overall health. As one can see by examining Table 4, physical attractiveness and good mental and physical health are the only two traits for which male ratings were higher than female ratings in three out of four cases.
The specifics for Malaysia are as follows: In the case of physical attractiveness, males were slightly, but not significantly, higher than females in rating this trait as being an important mate preference criterion. However, the trait of good mental and physical health was actually rated as being significantly more important to Malaysian females as a criterion for mate selection than it was to males. While somewhat contrary to theoretical expectations, it could be again reflecting the greater tendency by females to be discriminating in all ways with the exception of their prospective mate's physical attractiveness.

In the case of the US students, as theoretically predicted, males regarded physical attractiveness as more important for mate preference than did females. US males also considered good mental and physical health more important than did females, although the difference was not statistically significant. Overall, assuming that physical attractiveness and good mental and physical health are both indicative of reproductive potential, $\mathrm{H}_{3}$ was only modestly supported by our data. However, if physical attractiveness is considered the only real indicator of female reproductive potential, then our data are supportive of $\mathrm{H}_{3}$.

$\mathrm{H}_{4}$ Androgens and Overall Mate Preference Strength

As an enhanced evolutionary theory, the most novel feature of ENA theory is that it combines assumptions about neurohormonal processes with those involving natural selection. Specifically, androgens are hypothesized to be the main biochemical mechanisms whereby evolution has produced gender differences in the brain (and thereby in cognition and behavior). If so, low exposure to androgens should be associated with all manner of feminine traits. Conversely, high androgen exposure should correlate with all forms of masculine traits. These deductions should hold for evolved mate preferences.

Table 5 presents evidence bearing on $\mathrm{H}_{4}$. Specifically, regardless of an individual's gender, female-typical preferences should be more pronounced than male-typical preferences. This means that androgen exposure should be inversely correlated with the tendency to be unusually discriminating in one's mate preferences with the exception of preferences having to do with fecundity.

The column for factor 1 shows that most of the correlations for both countries are statistically significant and in the expected directions. In other words, except for good mental and physical health and physical attractiveness (to be discussed under $\mathrm{H}_{5}$ ), the vast majority of correlations indicate that low exposure to androgens (which is female-typical) is associated with increased tendencies to be choosey in mate preferences. One can see that the patterns were clearly present when males and females were analyzed together (coefficients outside the parentheses). When the correlations were 
performed after statistically controlling for gender (coefficients within the parentheses), the bulk of the coefficients were still highly significant among the Malaysian sample. For the US sample, 8 of the 12 coefficients were no longer statistically significant, although most of them remained negative in direction. Thus, $\mathrm{H}_{4}$ was confirmed regarding factor 1 , especially regarding the Malaysian sample.

A very different picture emerges when one examines the column for factor 2. It indicates that high levels of muscle-promoting androgen exposure are associated with increased, not decreased, tendencies to express highly discriminating mate preferences. Thus, androgen exposure associated with the MGMC factor appears to affect mate preferences in a very different way than the androgen exposure responsible for the BGNS factor.

$\mathrm{H}_{5}$ Androgens and Mate Preference for Health and Physical Attractiveness

According to ENA theory, high androgen exposure should diminish an individual's tendencies to be selective in choosing mates except in the case of selecting mates who are high in reproductive potential (fecundity). In terms of the 12 criteria used in the present study, the main traits indicative of fecundity would be good mental and physical health and physical attractiveness.

When discussing $\mathrm{H}_{4}$, we noted that nearly all of the correlations between factor 1 and the assessed importance of traits in mate preferences were inverse and statistically significant, thus supporting the hypothesis. Regarding $\mathrm{H}_{5}$, one can return to Table 5 to see that there are only two exceptions under factor 1: good mental and physical health and physical attractiveness for the US sample. In the case of physical attractiveness, the association with androgen exposure was statistically significant and positive rather than inverse for the US sample. For the good mental and physical health criterion, the association was slightly positive but nonsignificant. Overall, $\mathrm{H}_{5}$ is supported for the US sample. Regarding the Malaysian sample, however, the results for factor 1 failed to support $\mathrm{H}_{5}$ in that even after controlling for gender, significant

Table 5 Correlations between the two androgen-influenced factors and the 12 criteria for mate preferences according to country without and with gender controlled

\begin{tabular}{|c|c|c|c|}
\hline $\begin{array}{l}\text { Mate preference } \\
\text { trait }\end{array}$ & Country & $\begin{array}{l}\text { Factor 1: bone growth and neurosexing } \\
\text { factor (high values = high androgens) } \\
\text { (parentheses: gender controlled) }\end{array}$ & $\begin{array}{l}\text { Factor 2: muscularity and gross motor } \\
\text { coordination (high values = high androgens) } \\
\text { (parentheses: gender controlled) }\end{array}$ \\
\hline \multirow[t]{2}{*}{ Good financial prospects } & Malaysia & $-0.235 * * * *(-0.120 * * * *)$ & $0.099 * * * *(0.143 * * * *)$ \\
\hline & USA & $-0.185 * * * *(-0.123 * * * *)$ & $0.120 * * * *(0.153 * * * *)$ \\
\hline \multirow[t]{2}{*}{ Ambition and industriousness } & Malaysia & $-0.172 * * * *(-0.163 * * * *)$ & $0.151 * * * *(0.173 * * * *)$ \\
\hline & USA & $-0.202 * * * *\left(-0.111^{* * * *}\right)$ & $0.133 * * * *(0.170 * * * *)$ \\
\hline \multirow[t]{2}{*}{ Compatible family background } & Malaysia & $-0.148 * * * *(-0.163 * * * *)$ & $0.162 * * * *(0.175 * * * *)$ \\
\hline & USA & $-0.181 * * * *(-0.143 * * * *)$ & $0.152 * * * *(0.175 * * * *)$ \\
\hline \multirow[t]{2}{*}{ Desire for a home and children } & Malaysia & $-0.104 * * * *(-0.185 * * * *)$ & $0.172 * * * *(0.183 * * * *)$ \\
\hline & USA & $-0.156 * * * *(-0.083 * * *)$ & $0.102 * * * *(0.136 * * * *)$ \\
\hline \multirow[t]{2}{*}{ Personality compatibility } & Malaysia & $-0.089 * * *(-0.101 * * * *)$ & $0.095 * * * *(0.132 * * * *)$ \\
\hline & USA & $-0.068 * *(-0.022)$ & $0.041(0.060 *)$ \\
\hline \multirow[t]{2}{*}{ Intelligence and education } & Malaysia & $-0.180 * * * *(-0.167 * * * *)$ & $0.146^{* * * *}\left(0.169^{* * * *}\right)$ \\
\hline & USA & $-0.097 * * * *(-0.039)$ & $0.045(0.068)$ \\
\hline \multirow[t]{2}{*}{ Emotional stability } & Malaysia & $-0.083 * * *(-0.100 * * * *)$ & $0.087 * * *(0.114 * * * *)$ \\
\hline & USA & $-0.076^{* * *}(-0.025)$ & $0.019(0.029)$ \\
\hline \multirow[t]{2}{*}{ Having similar religious views } & Malaysia & $-0.151 * * * *(-0.197 * * * *)$ & $0.146 * * * *(0.171 * * * *)$ \\
\hline & USA & $-0.111 * * * *(-0.022)$ & $0.041\left(0.085^{* * *}\right)$ \\
\hline \multirow[t]{2}{*}{ Sense of humor } & Malaysia & $-0.139 * * * *(-0.113 * * * *)$ & $0.114 * * * *(0.132 * * * *)$ \\
\hline & USA & $-0.069 * *(-0.034)$ & $0.127 * * * *(0.143 * * * *)$ \\
\hline \multirow[t]{2}{*}{ Chastity (fidelity) } & Malaysia & $-0.121 * * * *(-0.094 * * * *)$ & $0.091 * * * *(0.110 * * * *)$ \\
\hline & USA & $-0.139 * * * *(-0.031)$ & $-0.033(-0.001)$ \\
\hline \multirow[t]{2}{*}{ Good mental and physical health } & Malaysia & $-0.111 * * * *(-0.151 * * * *)$ & $0.180 * * * *(0.203 * * * *)$ \\
\hline & USA & $0.005(-0.002)$ & $0.155^{* * * *}(0.158 * * * *)$ \\
\hline \multirow[t]{2}{*}{ Physical attractiveness (good looks) } & Malaysia & $-0.066 *(-0.164 * * * *)$ & $0.226 * * * *(0.228 * * * *)$ \\
\hline & USA & $0.122 * * * *(0.041)$ & $0.184 * * * *(0.164 * * * *)$ \\
\hline
\end{tabular}

Significance levels: $*<0.05 ; * *<0.01 ; * * *<0.005 ; * * * *<0.001$ 
negative correlations remain between preferences for both physical attractiveness and for good mental and physical health as mate choice criterion.

If one turns attention to factor 2 , Table 5 provides support for $\mathrm{H}_{5}$. Specifically, while factor 2 appears to promote discriminating tendencies for nearly all of the traits used in choosing mates (as discussed above in connection with $\mathrm{H}_{4}$ ), this tendency was especially strong for physical attractiveness. For both countries, these coefficients are higher than for any of the other mate preference criteria. This indicates that both males and females who are exposed to high MGMC androgens are especially inclined to focus on physical attractiveness as a mate selection criterion.

\section{Discussion}

In recent years, the application of evolutionary theory to the social sciences has opened these disciplines up to many innovative ways of thinking (Crawford and Krebs 2012; Mesoudi 2011; Wiley and Poston 1996). Nevertheless, a number of social scientists have criticized these applications for lacking empirical testability (e.g., Simon 1980; Vergne and Durand 2010). Such a criticism is rooted in the fact that, unlike evolutionary explanations for anatomical traits that can often be tested with fossil evidence, evolutionary explanations of cognitive and behavioral traits can almost never be tested this way.

Several enhancements of Darwin's (1859) theory of evolution by natural selection have been proposed to help explain gender differences in mating preferences and related behavior. As reviewed by Tappé et al. (2013), these include Kenrick and Trost's (1987) "good gene" theory (also see Kenrick et al. 2006), Buss and Schmitt's (1993) sexual strategy theory (SST), Gangestad and Simpson's (2000) strategic pluralism theory, Apostolou's (2007) parental selection theory, and Puts' (2010) intrasexual selection theory. However, none of these theories explicitly incorporates neurohormonal concepts into their arguments.

ENA theory was initially formulated to account for universal tendencies for males to be more criminal and antisocial than females (Ellis 2003, 2005) and later extended to explain all universal sex differences in behavior (Ellis 2011a, b). The theory's most unique feature is that it links the concept of natural (including sexual) selection with hormonal and neurological concepts. In other words, rather than simply using evolutionary logic to explain sex differences, or even adding assumptions about genetics to Darwin's original theory (as in the modern synthesis), ENA theory asserts that genes for neurohormonal variables have evolved to produce sex differences in many traits. As a result of this conceptual linkage, ENA theory leads one to expect that male and female brains have adapted the sexes to their respective reproductive roles. Males are hypothesized to be neurohormonally adapted for seeking to mate with multiple partners, especially if these prospective mates appear to be fertile, while females are neurohormonally adapted for restricting their mating activity to loyal partners capable of long-term resource provisioning (Ellis 2001; Townsend et al. 1995; Trivers 1972).

Once genes for androgens (and their metabolites) are envisioned as essential players in the evolution of gender differences in traits, one can deduce that because androgen exposure varies even within both sexes, within-sex variations will also exist in the traits for which there are average gender differences (Ellis 2011b). From this reasoning, numerous testable hypotheses flow. Put another way, if ENA theory is true, associations between androgens and behavior, even within each gender, should be detectable that mimic the betweengender differences for the same behaviors. For instance, the theory asserts that if males universally score higher than females on trait- $X$, then trait- $X$ must have been naturally (including sexually) selected and androgens must be responsible for enhancing trait-X. If this latter deduction is true, one should find a positive correlation between trait- $\mathrm{X}$ and androgen exposure even within samples of males and females. As explained below, this latter assumption provides an especially strong challenge to social scientists who continue to rely on social role and stereotype concepts to explain male-female differences in behavior.

\section{Challenging Social Environmental Theories}

Many social scientists still subscribe to theories that attribute all (or nearly all) sex differences in behavior to social traiting, stereotypes, and other sociocultural factors (e.g., Eagly 1997, 2013; Eagly and Wood 1999; Fausto-Sterling 1992). When called upon to account for why many sex differences in behavior are culturally universal, one feminist writer offered the following argument: "[T]he entire population of the world all evolved from a small progenitor stock" and universal behavioral sex differences "have been faithfully passed down a thousand times over" ever since (Fausto-Sterling 1992, p. 199). In other words, according to Fausto-Sterling, sex differences in behavior can be culturally maintained without being naturally selected. Doubters of such an explanation point to the tremendous diversity in cultures (including languages) as evidence that cultural universality in any aspect of human behavior requires more than a "founder effect" to be passed down a thousand times over in a single culture, let alone in all cultures. Nevertheless, Fausto-Sterling's explanation illustrates that it is possible to explain universal sex differences in behavior without mentioning natural selection.

Other social environmentalists have espoused what is known as social role theory. This theory explains sex 
differences in behavior by arguing that most sex differences are small. Then they point to the fact that the extent to which each sex differences exists varies from one culture to another (Eagly 1997, 2013; Eagly et al. 2000). From this line of reasoning, social role theorists can point to widespread cultural stereotypes about sex differences and to the sex role socialization practices that reinforce these stereotypes generation after generation (Eagly and Wood 1999; Eagly 2013). With these concepts, social role theorists are able to weave scenarios about how nearly every sex differences in behavior has come to be (Eagly 1997; Eagly and Wood 1999). With no fossils to challenge these explanations, social role theory remains credible to many if not most social scientists (e.g., Bettencourt and Miller 1996; Evers and Sieverding 2013; Franke et al. 1997; Harrison and Lynch 2005; Williams et al. 2010).

Parenthetically, social role theory's continued popularity also results from it being more compatible than evolutionary theory is with an egalitarian political-moral philosophy. Also, studies have shown that a wide swath of the social science community along with people in general prefers to attribute social problems and inequities (including those between the sexes) to sociopolitical factors rather than to biological factors (Diekman and Schneider 2010; Judge and Livingston 2008; Ridgeway 2006; Sanderson and Ellis 1992).

Setting political-moral issues aside, ENA theory adds a new dimension to empirically testing evolutionary explanations of universal sex differences in behavior. These tests are derived from the theory's assumption that if evolution is the "ultimate" cause of a given sex difference in behavior, then brain exposure to androgens must be a major "proximate" cause of the behavior. From this enhancement of traditional evolutionary accounts, one can deduce that even intrasex differences in universal sex differences in behavior should be the result of brain exposure to androgens. There is no way to make a similar prediction with social role theory. Therefore, social role theorists must do more to (in their minds) dismiss evolutionary explanations for sex differences in behavior than argue that these explanations are "after-the-fact just-so stories" (Gowaty 2003; Holcomb 1996). To dismiss ENA theory, critics must also demonstrate that neurohormonal factors are not contributing to the behavior in question even as those differences exist within each gender.

Instead of simply pitting the concepts of natural selection and sexual selection against the concepts of sex roles and stereotypes to account for sex differences in behavior, ENA adds neurohormonal concepts to its Darwinian scaffolding. While the relevance of neurohormonal variables for studying sex differences in behavior has been recognized as important by evolutionary psychologists for many years (e.g., Daly and Wilson 1978; Geary 2010; Low 2001; Mealey 2000), these variables have never before been explicitly interwoven with evolutionary arguments. Because it makes the link between evolution and neurohormonal proposition inseparable, ENA theory is more falsifiable than evolutionary theory is on its own. Nonetheless, it should be noted that ENA theory can only be applied to the study of traits for which sex differences have been demonstrated (or are at least suspected) as being universally present in human societies.

ENA theory gives evolutionary arguments additional credibility by showing that biology can explain universal sex differences in behavior not only in terms of differential reproduction but also in terms of evolved neurological and hormonal mechanisms. Furthermore, ENA theory even predicts that one can check the relevance of hormonal factors by making comparisons both between and within each sex. Put another way, ENA theory posits that any sexually dimorphic trait that is present across cultures has not only been naturally (including sexually) selected, but is also due to differential brain exposure to androgens, i.e., "male hormones," and their metabolites (Ellis 2011a, b). This premise is supported by evidence that many gender differences in preferences and behavior have evolutionary underpinnings (Kokko et al. 2003; Ryan and Rand 1993; Wiley and Poston 1996) but are also orchestrated by neuroandrogenic factors (Geary 2010; Hines 2006; Kimura 1992).

\section{Hypotheses Examined}

The present study tested five hypotheses, three of which were evolutionary in nature and two had to do with hormonal factors. $\mathrm{H}_{1}$ predicted that females would be more discriminating in choosing mates than males. Consistent with this prediction, most of the 12 criteria listed for mate selection were rated as more important by the female respondents ( $75 \%$ for Malaysia and $92 \%$ for the USA). This conforms to evolutionary arguments that reproductive choices are more consequential for females than for males.

$\mathrm{H}_{2}$ predicted that females would focus more than males on the resource-provisioning prospects of a potential mate. Consistent with expectations, the greatest gender differences in ratings in Malaysia were for good financial prospects and ambition and industriousness, with females surpassing males in their ratings of both traits. The US sample provided somewhat less support for $\mathrm{H}_{2}$ since only ambition and industriousness was significantly more important to females than to males.

The evidence bearing on $\mathrm{H}_{3}$ - that males would have greater interest than females in traits indicative of a prospective mate's reproductive potential-received partial confirmation. In the US sample, physical attractiveness was rated more important to males than to females. However, there was no gender difference in the rated importance of good mental and physical health as mate selection criteria. In the Malaysian sample, females considered good mental and physical health more important than did males, and there was no gender 
difference among Malaysians on ratings of the importance of physical attractiveness.

$\mathrm{H}_{4}$ stated that low exposure to androgens would be associated with preference for female-preferred traits, as established regarding $\mathrm{H}_{1}$. Theoretically, $\mathrm{H}_{4}$ should hold even after controlling for gender and should be especially strong for traits indicative of loyalty and resource procurement capabilities. Consistent with this hypothesis, in the samples drawn from both countries, factor 1 was inversely associated with nearly all of the mate preference traits to significant degrees even after controlling for gender. Regarding the traits that are most indicative of loyalty and resource procurement capabilities, the evidence is generally supportive given that three of the four strongest correlations with factor 1 for both countries involved good financial prospects, ambition and industriousness, and intelligence and education.

According to $\mathrm{H}_{5}$, high prenatal androgen exposure should be associated with preference for male-typical traits. Table 5 provides support for this hypothesis in the case of the US sample, but very little regarding the Malaysian sample. Rather surprisingly, Table 5 suggests that all forms of mate discrimination (i.e., both male-typical and female-typical) are amplified by exposure to androgens that enhance muscle growth and motor coordination (factor 2). In other words, for both sexes in both countries, high androgen exposure associated with muscularity and gross motor coordination was associated with being choosy regarding nearly all types of mate characteristics. Nevertheless, as expected, the trait that correlated most strongly with high factor 2 androgen exposure involved preferring mates who were physically attractive.

\section{The Androgen Factors}

The present study would not have been possible without a way of inferring variations in androgen exposure. In recent years, a common way of making such an inference has involved measuring the relative length of the second and fourth fingers, known as 2D:4D (e.g., Galis et al. 2010; Manning et al. 2013). While recognizing its basic validity, several researchers who have utilized 2D:4D measures note that it lacks precision (Hauth et al. 2014, p. 491; Hell and Paßler 2011; Medland et al. 2010). Studies can at least partially overcome 2D:4D's lack of precision by using large samples (Manning and Fink 2008) - which the present study did — but we also decided to try to improve measurement further by factor analyzing our 2D:4D along with nine other androgen-influenced traits.

We consider this approach to be superior to making inferences about androgen exposure from a one-time saliva or blood sample in light of two established facts: First, testosterone levels were very considerably even over the course of a single day, let alone variations occurring over longer periods of time (Ellison and Panter-Brick 1996; Hirschenhauser et al. 2002; Vitzthum et al. 2009). Second, nearly all of the effects that testosterone has on brain functioning require weeks or even months to be consequential during fetal development (Lombardo et al. 2012) and seem to require months or even years to impact brain functioning in the case of postpubertal exposure (Granger et al. 2004).

In light of the extended time frames over which testosterone produces measurable effects on brain functioning, it is difficult to make inferences about brain effects using onetime blood or saliva assays (Granger et al. 2004). Also, evidence has increasingly indicated that it is prenatal testosterone rather than postpubertal testosterone that has the most enduring effects on brain functioning (and thereby on behavior) (Earl Gray et al. 2006; Thor and Holloway 1985). In other words, androgens have their most permanent effects on traits prior to birth (when the brain is being fundamentally formed), and the effects of postpubertal exposure to androgens are largely limited to simply engaging and accentuating whatever predispositions were established prenatally (Evuarherhe et al. 2009; Schulz et al. 2009).

We believe that the approach taken in the present study of factor analyzing several known androgen-influenced physiological traits provides a promising alternative to estimating androgen exposure with (a) one-time androgen samples and even (b) 2D:4D by itself. But others need to independently investigate this possibility.

The two factors that emerged from factor analyzing the androgen-influenced traits were a challenge to precisely name. We initially thought that factor 1 could be identified as a prenatal androgen factor and factor 2 a postpubertal androgen factor, given that r2D:4D only loaded onto the first factor (albeit modestly). However, in carefully scrutinizing the literature (as discussed in the "Methods" section), we eventually decided to give the two factors names that precisely depicted the actual traits each factor engulfed. This decision was primarily based on concluding that prenatal androgens appear to play critical roles in affecting all of the traits covered by both factors, i.e., bone growth and neurosexual differentiation (factor 1) and musculature and athletic ability (factor 2). Nevertheless, additional studies are needed using an even greater number of androgen-influenced variables to verify our conclusions about androgen factors.

\section{Indirect Versus Direct Selection}

As stated in the "Introduction," ENA theory asserts that all universal sex differences in cognition and behavior are due to natural (including sexual) selection. A key qualification to this assertion is that some universal sex differences may be indirectly selected, rather than directly selected. An example discussed in the "Introduction" involved the mental/ behavioral condition known as autism. Another widely studied condition could be depression, which is more common among females than among males (reviewed by Ellis et al. 
2008, pp. 364-376). To illustrate how a sex difference in depression could have evolved via indirect processes, Nesse (2000) has proposed that the high concentration of depression among females could be due to mild to moderate forms of depression promoting female reproduction. In particular, females with even mild forms of depression may be less likely to pursue career activities that reduce their rates of reproduction. Thereby, these women would pass their genes on at higher rates than females with no depressive symptoms.

As noted earlier, male tendencies to exhibit autism more than females could also have been naturally selected because genes that promote autism could have been favored because in mild forms, these genes promote occupational interests in engineering and science that often made such males attractive to females as capable resource provisioners (Baron-Cohen et al. 1997; Kanazawa and Vandermassen 2005).

\section{Strengths and Limitations of the Study}

The fact that we were able to test our hypotheses using large sample sizes from two distinct countries bolsters confidence in its findings. Nevertheless, some of the results were not the same for the Malaysian and US samples, suggesting that more research is needed. For instance, our failure to find a significant gender difference in the assessed importance of physical attractiveness as a mate selection criterion in our Malaysian sample was surprising and at odds with our confirming the well-established tendency for males to consider physical attractiveness more important than females in the US sample.

Because ENA theory makes predictions about all universal gender differences in cognition and behavior, the present study is obviously limited in considering only a few of these predictions, i.e., ones pertaining to mate preferences. Also, to test key aspects of ENA theory requires being able to measure androgen exposure, especially prenatal exposure. We chose to base our measurement on respondents' self-reports of various androgen-promoted physiological traits, only one of which was the 2D:4D ratio. Even this approach, however, has at least two noteworthy limitations: First, according to ENA theory, it is brain exposure to androgens, not peripheral exposure, which influences gender differences in behavior. Obviously, the fact that we based our measures of androgen exposure entirely on peripheral indicators of exposure rather than neurological indicators is a weakness. Nevertheless, studies have indicated that brain exposure to androgens and overall bodily exposure are positively correlated to a substantial degree (Hrabovszky and Hutson 2002; Swerdloff et al. 1992).

Second, the androgen exposure measures used in this study were all derived from self-reports rather than from either assays of blood or saliva or actual physical measurements by trained observers. While it would be informative to have had these more direct androgen measurements, doing so would have been costly, invasive, and would have compromised the anonymity of the study participants. Furthermore, we actually doubt that blood or saliva assays would have been superior to the self-report measures herein utilized for the following reasons:

1. ENA theory pertains to the effects of long-term androgen exposure (i.e., at least weekly or monthly), not the effects of short-term exposure (i.e., hourly or daily). Obtaining blood or saliva samples only provides short-term exposure measurement. While momentary androgen levels are likely to positively correlate with long-term exposure levels, physiological traits as masculine and feminine mannerisms, 2D:4D ratios, and depth of voice are more likely to reflect the effects of long-term androgen exposure.

2. Regarding the two stages of androgen exposure, ENA theory asserts that prenatal levels are more important for permanently sexing cognitive and behavioral traits. Saliva or blood assays following puberty may well correlate with prenatal levels, but only modestly, in all likelihood (Forest 2008).

The above reasoning led us to conclude that rather than obtaining a single peripheral measure of androgens in saliva or blood, it was preferable to estimate androgen exposure with multiple physical traits that are known to be androgeninfluenced and then factor analyze the results. We were encouraged in this regard by the discovery that a two-factor solution arose in our samples from both countries. Nevertheless, the fact that we used mainly peripheral measures rather than neurological measures remains a weakness in our study since ENA theory asserts that it is brain exposure that is required to alter cognitive and behavioral traits.

Also, because we relied on self-reported information to measure our androgen-influenced traits, and used these traits to construct our androgen factors, it is possible to offer a strictly social (nonbiological) explanation for our findings. The pattern of such an explanation would be as follows: Men who perceive themselves to be unusually feminine (e.g., to be at least somewhat feminine in appearance and mannerisms) might coincidentally gravitate toward holding relatively feminine attitudes regarding what they desire in terms of a prospective mate. For instance, these self-perceived "feminine males" might prefer males with good financial prospects more than self-perceived "masculine males." Likewise, women who perceive themselves to be unusually masculine could gravitate toward mate preferences that are more feminine than for females who perceive themselves to be unusually feminine.

However, we are inclined to doubt the above arguments partly because one of the self-report measures used to construct the two androgen factors was height, a trait that has been shown to be reliably measured with self-reports. That is to say 
that self-reported height and objectively measured height have been shown to correlate at 0.80 or above (Blais et al. 2013; $\mathrm{Ng}$ et al. 2011). Unfortunately, other self-reported traits - particularly those involving the second factor (physical strength, muscularity, and athletic ability) - do not appear to have been investigated regarding their consistency with actual physical measurements. Ultimately, the only certain way to determine if socially constructed self-perceptions can explain our findings would be to conduct one or more studies in which androgen exposure is assessed primarily using a variety of physiological measures and then compare these objective measures to self-report measures.

Another limitation of the present study involved our failure to utilize a more exhaustive list of criteria by which males and females might express preferences for mates. For example, it would have been informative to have included traits such as an active sex life and compatible political views as criteria for choosing a mate. Nevertheless, with the criteria that were included, we were able to show that numerous relationships between mate preference criteria and varying degrees of apparent exposure to androgens exist, even within each gender.

Finally, there may be substantial ethnic/racial differences in androgen exposure and in how this exposure impacts sexually dimorphic traits (Ellis and Nyborg 1992; McIntyre 2006; Perry and Martin 2014). While the confounding effect of ethnic/ racial differences in androgen exposure calls for more research attention, its relevance to our study was somewhat diminished by analyzing our results separately by country.

\section{Conclusions}

According to ENA theory, evolution has driven a semiporous wedge between males and females in terms of preferences for mates as well as many other cognitive and behavioral traits. Since females must invest the most in each offspring conceived, they have been favored for preferring mates who are capable resource provisioners (Ellis 2001). Males, on the other hand, focus their mate preferences on evidence of fecundity (Gangestad and Simpson 2000). Predictions from this evolutionary aspect of the theory were largely supported in the US sample and moderately supported in the Malaysian sample.

ENA theory goes on to assert that this semiporous wedge is orchestrated by genes that cause males to produce much higher amounts of androgens than are produced by females. These androgens operate throughout the body, including the nervous system, thereby affecting numerous aspects of cognition and behavior (Ellis 2011b; Ellis and Hoskin 2015). While neither the evolutionary element nor the neuroandrogenic element of ENA theory is unique, combining these two elements into a single theory of universal sex differences in cognition and behavior is distinctive. Furthermore, ENA theory allows one to infer that intragender variability in these neuroandrogenic processes will produce intragender variability in cognition and behavior consistent with average between-gender differences in these traits. This latter inference makes ENA theory highly vulnerable to disproof.

Several recent studies have indicated that the prenatal stage of androgen exposure is more crucial than the postpubertal stage for producing permanent gender differences in brain functioning (Auyeung et al. 2009; Baron-Cohen et al. 2005; Hines 2006). Findings from the present study coincide with this conclusion. In essence, low (female-typical) prenatal androgen exposure appears to promote feminine-like mate preferences - i.e., high discrimination but with a focus on a prospective mate's stability and resource procurement tendencies. To a lesser degree, high (male-typical) prenatal androgen seems to promote masculinized mate preferences-i.e., low discrimination with a focus on a prospective mate's fecundity prospects. Both of these effects should be detectable not only between males and females, but among them separately.

In closing, the first major enhancement of Darwin's theory came to be known as the modern synthesis. It marked the merging of the concept of natural selection with the emerging field of genetics (Huxley 1942; Mayr 1998; Rose and Oakley 2007). ENA theory dovetails with the modern synthesis by arguing that gender differences in brain functioning have evolved from genetic programs that sexually differentiate exposure to sex hormones. The theory also asserts that in the case of universal cognitive and behavioral sex differences, female-typical preferences should be associated with low androgen exposure and male-typical preferences should be associated with high androgen exposure even within each gender. In the present study, general support was found for these deductions. With more reliable measures of androgen exposure, we believe that stronger associations are likely to emerge.

Acknowledgments We thank the following persons for helping to recruit research participants for this study: Drew H. Bailey, David Geary, Richard D. Hartley, Anthony Hoskins, Richard Lippa, Emi Prihatin, David Puts, Anthony Walsh, and Alan Widmayer. The collection of data utilized in this study was funded in part by a grant (Number RG14310HNE) to the Department of Anthropology and Sociology from the University of Malaya.

\section{References}

Apostolou, M. (2007). Sexual selection under parental choice: the role of parents in the evolution of human mating. Evolution and Human Behavior, 28, 403-409.

Auyeung, B., Baron-Cohen, S., Ashwin, E., Knickmeyer, R., Taylor, K., Hackett, G., \& Hines, M. (2009). Fetal testosterone predicts sexually differentiated childhood behavior in girls and in boys. Psychological Science, 20, 144-148.

Balmford, A., Rosser, A. M., \& Albon, S. D. (1992). Correlates of female choice in resource-defending antelope. Behavioral Ecology and Sociobiology, 31, 107-114. 
Baron-Cohen, S. (2008). Autism and Asperger syndrome. New York: Oxford University Press.

Baron-Cohen, S., Wheelwright, S., Stott, C., Bolton, P., \& Goodyer, I. (1997). Is there a link between engineering and autism? Autism: An International Journal of Research and Practice, 1, 153-163.

Baron-Cohen, S., Knickmeyer, R. C., \& Belmonte, M. K. (2005). Sex differences in the brain: implications for explaining autism. Science, 310, 819-823.

Bell, D. S., MacDonald, P. K., \& Thayer, B. A. (2001). Start the evolution without us. International Security, 26, 187-198.

Benbow, C. P. (1988). Sex differences in mathematical reasoning ability in intellectually talented preadolescents: their nature, effects, and possible causes. Behavioral and Brain Sciences, 11, 169-183.

Bereczkei, T., Voros, S., Gal, A., \& Bernath, L. (1997). Resources, attractiveness, family commitment: reproductive decisions in human mate choice. Ethology, 103, 681-699.

Berenbaum, S. A., \& Beltz, A. M. (2011). Sexual differentiation of human behavior: effects of prenatal and pubertal organizational hormones. Frontiers in Neuroendocrinology, 32, 183-200.

Berenbaum, S. A., Bryk, K. K., Nowak, N., Quigley, C. A., \& Moffat, S. (2009). Fingers as a marker of prenatal androgen exposure. Endocrinology, 150, 5119-5124.

Bettencourt, B., \& Miller, N. (1996). Gender differences in aggression as a function of provocation: a meta-analysis. Psychological Bulletin, 119, 422-447.

Bhasin, S., Stores, T. W., Berman, N., Callegari, C., Clevenger, B., Phillips, J., Bunnell, T. J., Tricker, R., Shirazi, A., \& Casaburi, R. (1996). The effects of supraphysiologic doses of testosterone on muscle size and strength in normal men. New England Journal of Medicine, 335, 1-7.

Blais, L., Lemiere, C., Jacob, A., \& Lavoie, K. (2013). Reliability and accuracy of self-reported versus measured height, height, and body mass index in patients with asthma. American Journal of Respiratory Critical Care Medicine, 187, A4206.

Boyd, B. (1998). Jane, meet Charles: literature, evolution, and human nature. Philosophy and Literature, 22, 1-30.

Bradshaw, C., Kahn, A. S., \& Saville, B. K. (2010). To hook up or date: which gender benefits? Sex Roles, 62, 661-669.

Breedlove, S. M. (2010). Mini-review: Organizational hypothesis: instances of the fingerpost. Endocrinology, 151, 4116-4122.

Breedlove, S. M., \& Hampson, E. (2002). Sexual differentiation of the brain and behavior. In J. B. Becker, S. M. Breedlove, S. M. Crews, \& D. M. McCathy (Eds.), Behavioral endocrinology (Vol. 2, pp. 360-369). Cambridge, MS: MIT Press.

Brown, W. M., Finn, C. J., Cooke, B. M., \& Breedlove, S. M. (2002). Differences in finger length ratios between self-identified "butch" and "femme" lesbians. Archives of Sexual Behavior, 31, 123-127.

Buss, D. M. (1995). Evolutionary psychology: a new paradigm for psychological science. Psychological Inquiry, 6, 1-30.

Buss, D. M., \& Schmitt, D. (1993). Sexual strategies theory: an evolutionary perspective on human mating. Psychological Review, 100, 204-232.

Buss, D. M., Shackelford, T. K., Kirkpatrick, L. A., \& Larsen, R. J. (2001). A half century of mate preferences: the cultural evolution of values. Journal of Marriage and Family, 63, 491-503.

Buyken, A. E., Karaolis-Danckert, N., \& Remer, T. (2009). Association of prepubertal body composition in healthy girls and boys with the timing of early and late pubertal markers. American Journal of Clinical Nutrition, 89, 221-230.

Cahill, L. (2006). Why sex matters for neuroscience. Nature Reviews Neuroscience, 7, 477-484.

Cameron, D. (2010). Sex/gender, language and the new biologism. Applied Linguistics, 31, 173-192.

Collaer, M. L., \& Hines, M. (1995). Human behavioral sex differences: a role for gonadal hormones during early development? Psychological Bulletin, 118, 55-107.
Confer, J. C., Easton, J. A., Fleischman, D. S., Goetz, C. D., Lewis, D. M., Perilloux, C., \& Buss, D. M. (2010). Evolutionary psychology: controversies, questions, prospects, and limitations. American Psychologist, 65, 110-126.

Cotton, S., Small, J., \& Pomiankowski, A. (2006). Sexual selection and condition-dependent mate preferences. Current Biology, 16, R755R765.

Cox, D. (2007). Biological basics and the economics of the family. Journal of Economic Perspectives, 21, 91-108.

Crawford, C., \& Krebs, D. (Eds.). (2012). Foundations of evolutionary psychology. New York: Psychology Press.

Crews, D., \& Moore, M. C. (1986). Evolution of mechanisms controlling mating behavior. Science, 231(4734), 121-125.

Daly, M., \& Wilson, M. (1978). Sex, evolution and behavior. North Scituate, Massachusetts: Duxbury Press.

Daly, M., \& Wilson, M. I. (1999). Human evolutionary psychology and animal behaviour. Animal Behaviour, 57, 509-519.

Daly, R., Saxon, L., Turner, C., Robling, A., \& Bass, S. (2004). The relationship between muscle size and bone geometry during growth and in response to exercise. Bone, 34, 281-287.

Demski, L. S. (1984). The evolution of neuroanatomical substrates of reproductive behavior: sex steroid and LHRH-specific pathways including the terminal nerve. American Zoologist, 24, 809-830.

Diekman, A. B., \& Schneider, M. C. (2010). A social role theory perspective on gender gaps in political attitudes. Psychology of Women Quarterly, 34, 486-497.

DiPrete, T. A., \& Buchmann, C. (2006). Gender-specific trends in the value of education and the emerging gender gap in college completion. Demography, 43, 1-24.

Eagly, A. H. (1997). Sex differences in social behavior: comparing social role theory and evolutionary psychology. American Psychologist, $52,380-1383$.

Eagly, A. H. (2013). Sex differences in social behavior: a social-role interpretation. New York: Psychology Press.

Eagly, A. H., \& Wood, W. (1999). The origins of sex differences in human behavior: evolved dispositions versus social roles. American Psychologist, 54, 408-423.

Eagly, A. H., Wood, W., Diekman, A. B. (2000). Social role theory of sex differences and similarities: a current appraisal. The Developmental Social Psychology of Gender, 123-174.

Earl Gray, L., Wilson, V. S., Stoker, T., Lambright, C., Furr, J., Noriega, N., \& Guillette, L. (2006). Adverse effects of environmental antiandrogens and androgens on reproductive development in mammals. International Journal of Andrology, 29, 96-104.

Edward, D. A., \& Chapman, T. (2011). The evolution and significance of male mate choice. Trends in Ecology \& Evolution, 26(12), 647-654.

Ellis, L. (1995). Dominance and reproductive success among nonhuman animals: a cross-species comparison. Ethology and Sociobiology, $16,257-333$.

Ellis, L. (2001). The biosocial female choice theory of social stratification. Social Biology, 48, 298-320.

Ellis, L. (2003). Genes, criminality, and evolutionary neuroandrogenic theory. In A. Walsh \& L. Ellis (Eds.), Biosocial criminology: challenging environmentalism's supremacy (pp. 13-34). New York: Nova Science.

Ellis, L. (2005). Theoretically explaining biological correlates of criminal behavior. European Journal of Criminology, 2, 287-315.

Ellis, L. (2011a). Evolutionary neuroandrogenic theory and universal gender differences in cognition and behavior. Sex Roles, 64, 707722.

Ellis, L. (2011b). Identifying and explaining apparent universal sex differences in cognition and behavior. Personality and Individual Differences, 51, 552-561.

Ellis, L., Hoskin, A. (2015). Criminality and the 2D:4D ratio: testing the prenatal androgen hypothesis. International Journal of Offender Therapy and Comparative Criminology, 59, 295-312. 
Ellis, L., \& Nyborg, H. (1992). Racial/ethnic variations in male testosterone levels: a probable contributor to group differences in health. Steroids, 57, 72-75.

Ellis, L., Hershberger, S., Field, E., Wersinger, S., Pellis, S., Geary, D., Palmer, C., Hoyenga, K., Hetsroni, A., \& Karadi, K. (2008). Sex differences: summarizing more than a century of scientific research. New York: Psychology Press.

Ellison, P. T., \& Panter-Brick, C. (1996). Salivary testosterone levels among Tamang and Kami males of central Nepal. Human Biology, 68, 955-965.

Evans, S., Neave, N., \& Waklin, D. (2006). Relationships between vocal characteristics and body size and shape in human males: an evolutionary explanation for a deep male voice. Biological Psychology, $72,160-163$

Evers, A., Sieverding, M. (2013). Why do highly qualified women (still) earn less? Gender differences in long-term predictors of career success. Psychology of Women Quarterly, 0361684313498071.

Evuarherhe, O., Leggett, J. D., Waite, E. J., Kershaw, Y. M., Atkinson, H. C., \& Lightman, S. L. (2009). Organizational role for pubertal androgens on adult hypothalamic-pituitary-adrenal sensitivity to testosterone in the male rat. Journal of Physiology, 587, 2977-2985.

Fausto-Sterling, A. (1992). Myths of gender: biological theories about women and men. New York: Basic Books.

Fink, B., Thanzami, V., Seydel, H., \& Manning, J. T. (2006). Digit ratio and hand-grip strength in German and Mizos men: cross-cultural evidence for an organizing effect of prenatal testosterone on strength. American Journal of Human Biology, 18, 776-782.

Firebaugh, G., \& Dorius, S. F. (2010). Trends in global gender inequality. Social Forces, 88, 1941-1968.

Forest, M. G. (2008). Role of androgens in fetal and pubertal development. Hormone Research in Pcediatrics, 18, 69-83.

Franke, G. R., Crown, D. F., \& Spake, D. F. (1997). Gender differences in ethical perceptions of business practices: a social role theory perspective. Journal of Applied Psychology, 82, 920-934.

Galis, F., Ten Broek, C. M., Van Dongen, S., \& Wijnaendts, L. C. (2010). Sexual dimorphism in the prenatal digit ratio (2D:4D). Archives of Sexual Behavior, 39, 57-62.

Gangestad, S. W., \& Simpson, J. A. (2000). The evolution of human mating: trade-offs and strategic pluralism. Behavioral and Brain Sciences, 23, 573-587.

Geary, D. C. (2010). Male, female: the evolution of human sex differences (2nd ed.). Washington, DC: American Psychological Association.

Geary, D. C., Vigil, J., \& Byrd-Craven, J. (2004). Evolution of human mate choice. Journal of Sex Research, 41, 27-42.

Gottfredson, L. S. (2003). The challenge and promise of cognitive career assessment. Journal of Career Assessment, 11, 115-135.

Gowaty, P. A. (2003). Sexual natures: how feminism changed evolutionary biology. Signs, 28(3), 901-921.

Granger, D. A., Shirtcliff, E. A., Booth, A., Kivlighan, K. T., \& Schwartz, E. B. (2004). The "trouble" with salivary testosterone. Psychoneuroendocrinology, 29, 1229-1240.

Gray, P. B., \& Garcia, J. R. (2013). Evolution and human sexual behavior. Cambridge, MA: Harvard University Press.

Greenlees, I. A., \& McGrew, W. C. (1994). Sex and age differences in preferences and tactics of mate attraction: analysis of published advertisements. Ethology and Sociobiology, 15, 59-72.

Grimbos, T., Dawood, K., Burriss, R. P., Zucker, K. J., \& Puts, D. A. (2010). Sexual orientation and the second to fourth finger length ratio: a meta-analysis in men and women. Behavioral Neuroscience, 124, 278-287.

Harrison, L. A., \& Lynch, A. B. (2005). Social role theory and the perceived gender role orientation of athletes. Sex Roles, 52, 227-236.

Hauth, I., Bruijn, Y. G., Staal, W., Buitelaar, J. K., \& Rommelse, N. N. (2014). Testing the extreme male brain theory of autism spectrum disorder in a familial design. Autism Research, 7, 491-498.
Hell, B., \& Paßler, K. (2011). Are occupational interests hormonally influenced? The 2D:4D-interest nexus. Personality and Individual Differences, 51, 376-380.

Hines, M. (2006). Prenatal testosterone and gender-related behaviour. European Journal of Endocrinology, 155, S115-S121.

Hirschenhauser, K., Frigerio, D., Grammer, K., \& Magnusson, M. S. (2002). Monthly patterns of testosterone and behavior in prospective fathers. Hormones and Behavior, 42, 172-181.

Holcomb, H. R., III. (1996). Just so stories and inference to the best explanation in evolutionary psychology. Minds and Machines, 6 , $525-540$

Hönekopp, J., \& Schuster, M. (2010). A meta-analysis on 2D: 4D and athletic prowess: substantial relationships but neither hand outpredicts the other. Personality and Individual Differences, 48, 4-10.

Hönekopp, J., \& Watson, S. (2010). Meta-analysis of digit ratio 2D:4D shows greater sex difference in the right hand. American Journal of Human Biology, 22, 619-630.

Hönekopp, J., Manning, J. T., \& Müller, C. (2006). Digit ratio (2D:4D) and physical fitness in males and females: evidence for effects of prenatal androgens on sexually-selected traits. Hormones and Behavior, 49, 545-549.

Hrabovszky, Z., \& Hutson, J. M. (2002). Androgen imprinting of the brain in animal models and humans with intersex disorders: review and recommendations. Journal of Urology, 168, 2142-2148.

Huxley, J. (1942). Evolution. The modern synthesis. London: Allen \& Unwin.

Inglis, J. G., Vandenboom, R., \& Gabriel, D. A. (2013). Sex-related differences in maximal rate of isometric torque development. Journal of Electromyography and Kinesiology, 23, 1289-1294.

Jennions, M. D., \& Petrie, M. (1997). Variation in mate choice and mating preferences: a review of causes and consequences. Biological Reviews, 72, 283-327.

Judge, T. A., \& Livingston, B. A. (2008). Is the gap more than gender? A longitudinal analysis of gender, gender role orientation, and earnings. Journal of Applied Psychology, 93, 994-1012.

Kanazawa, S., \& Vandermassen, G. (2005). Engineers have more sons, nurses have more daughters: an evolutionary psychological extension of Baron-Cohen's extreme male brain theory of autism. Journal of Theoretical Biology, 233, 589-599.

Kastlunger, B., Dressler, S. G., Kirchler, E., Mittone, L., \& Voracek, M. (2010). Sex differences in tax compliance: differentiating between demographic sex, gender-role orientation, and prenatal masculinization (2D:4D). Journal of Economic Psychology, 31, 542-552.

Keller, M. C., \& Miller, G. (2006). Resolving the paradox of common, harmful, heritable mental disorders: which evolutionary genetic models work best? Behavioral and Brain Sciences, 29, 385-404.

Kenrick, D. T., \& Keefe, R. C. (1992). Age preferences in mates reflect sex differences in human reproductive strategies. Behavioral and Brain Sciences, 15, 75-91.

Kenrick, D. T., \& Trost, M. R. (1987). A biosocial theory of heterosexual relationships. In K. Kelley (Ed.), Females, males, and sexuality: theories and research (pp. 59-100). Albany, NY: SUNY Press.

Kenrick, D. T., Sadalla, E. K., Groth, G., \& Trost, M. R. (1990). Evolution, traits, and the stages of human courtship: qualifying the parental investment model. Journal of Personality, 58, 97-116.

Kenrick, D., Ackerman, J., \& Ledlow, S. (2006). Evolutionary social psychology: adaptive predispositions and human culture. In J. Delamater (Ed.), Handbook of social psychology (pp. 103-122). New York: Springer.

Kimura, D. (1992). Sex differences in the brain. Scientific American, 267(3), 118-125.

Kirkpatrick, M., \& Ryan, M. J. (1991). The evolution of mating preferences and the paradox of the lek. Nature, 350, 33-38.

Kokko, H., Brooks, R., Jennions, M. D., \& Morley, J. (2003). The evolution of mate choice and mating biases. Proceedings of the Royal Society of London B, 270, 653-664. 
Langdon, D., McKittrick, G., Beede, D., Khan, B., \& Doms, M. (2011). STEM: good jobs now and for the future. ESA Issue Brief\# 03-11. Washington, DC: U.S. Department of Commerce.

Lee, S., Potamianos, A., \& Narayanan, S. (1999). Acoustics of children's speech: developmental changes of temporal and spectral parameters. Journal of the Acoustical Society of America, 105, 1455-1468.

Lombardo, M. V., Ashwin, E., Auyeung, B., Chakrabarti, B., Taylor, K., Hackett, G., \& Baron-Cohen, S. (2012). Fetal testosterone influences sexually dimorphic gray matter in the human brain. Journal of Neuroscience, 32, 674-680.

Loos, R., Thomis, M., Maes, H., Beunen, G., Claessens, A., Derom, C., \& Vlietinck, R. (1997). Gender-specific regional changes in genetic structure of muscularity in early adolescence. Journal of Applied Physiology, 82, 1802-1810.

Low, B. S. (2001). Why sex matters: a Darwinian look at human behavior. Princeton, NJ: Princeton University Press.

Lubinski, D., \& Benbow, C. P. (2006). Study of mathematically precocious youth after 35 years: uncovering antecedents for the development of math-science expertise. Perspectives on Psychological Science, 1, 316-345.

Malina, R. M. (1978). Growth of muscle tissue and muscle mass. In F. Faulkner (Ed.), Human growth (pp. 273-294). New York: Springer.

Manning, J. T. (2011). Resolving the role of prenatal sex steroids in the development of digit ratio. Science Signaling, 108, 16143-16144.

Manning, J. T., \& Fink, B. (2008). Digit ratio (2D:4D), dominance, reproductive success, asymmetry, and sociosexuality in the BBC internet study. American Journal of Human Biology, 20, 451-461.

Manning, J. T., Scutt, D., Wilson, J., \& Lewis-Jones, D. I. (1998). The ratio of 2 nd to 4th digit length: a predictor of sperm numbers and concentrations of testosterone, luteinizing hormone and oestrogen. Human Reproduction, 13, 3000-3004.

Manning, J. T., Fink, B., Neave, N., \& Caswell, N. (2005). Photocopies yield lower digit ratios (2D:4D) than direct finger measurements. Archives of Sexual Behavior, 34, 329-333.

Manning, J. T., Churchill, A. J. G., \& Peters, M. (2007a). The effects of sex, ethnicity, and sexual orientation on self-measured digit ratio (2D:4D). Archives of Sexual Behavior, 36, 223-233.

Manning, J. T., Morris, L., \& Caswell, N. (2007b). Endurance running and digit ratio (2D:4D): implications for fetal testosterone effects on running speed and vascular health. American Journal of Human Biology, 19, 416-421.

Manning, J., Kilduff, L., \& Trivers, R. (2013). Digit ratio (2D:4D) in Klinefelter's syndrome. Andrology, 1, 94-99.

Marlowe, F. W. (2004). Mate preferences among Hadza hunter-gatherers. Human Nature, 15, 365-376.

Mayr, E. (1998). The evolutionary synthesis: perspectives on the unification of biology. Cambridge: Harvard University Press.

McFadden, D., \& Bracht, M. S. (2005). Sex differences in the relative lengths of metacarpals and metatarsals in gorillas and chimpanzees. Hormones and Behavior, 47, 99-111.

McIntyre, M. H. (2006). The use of digit ratios as markers for perinatal androgen action. Reproductive Biology and Endocrinology, 4, 1-9.

Mealey, L. (2000). Sex differences: developmental and evolutionary strategies. New York: Academic.

Medland, S. E., Zayats, T., Glaser, B., Nyholt, D. R., Gordon, S. D., Wright, M. J., et al. (2010). A variant in LIN28B is associated with 2D:4D finger-length ratio, a putative retrospective biomarker of prenatal testosterone exposure. American Journal of Human Genetics, $86,519-525$.

Mesoudi, A. (2011). Cultural evolution: how Darwinian theory can explain human culture and synthesize the social sciences. Chicago: University of Chicago Press.

Moore, F. R., Cassidy, C., Law Smith, M. J., \& Perrett, D. I. (2006). The effects of female control of resources on sex-differentiated mate preferences. Evolution and Human Behavior, 27, 193-205.
Nesse, R. M. (2000). Is depression an adaptation? Archives of General Psychiatry, 57, 14-20.

Neu, C. M., Rauch, F., Rittweger, J., Manz, F., \& Schoenau, E. (2002). Influence of puberty on muscle development at the forearm. American Journal of Physiology, Endocrinology and Metabolism, 283, E103-E107.

Ng, S. P., Korda, R., Clements, M., Latz, I., Bauman, A., Bambrick, H., \& Banks, E. (2011). Validity of self-reported height and weight and derived body mass index in middle-aged and elderly individuals in Australia. Australian and New Zealand Journal of Public Health, 35, 557-563.

Perry, A. C., \& Martin, L. (2014). Race differences in obesity and its relationship to the sex hormone milieu. Hormone Molecular Biology and Clinical Investigation, 19, 151-161.

Perusse, D. (1994). Mate choice in modern societies: testing evolutionary hypotheses with behavioral data. Human Nature, 5, 255-278.

Pizzari, T. (2003). Food, vigilance, and sperm: the role of male direct benefits in the evolution of female preferences in a polygamous bird. Behavioral Ecology, 14, 593-601.

Puts, D. A. (2010). Beauty and the beast: mechanisms of sexual selection in humans. Evolution and Human Behavior, 31, 157-175.

Puts, D. A., Apicella, C. L., \& Cárdenas, R. A. (2012). Masculine voices signal men's threat potential in forager and industrial societies. Proceedings of the Royal Society B: Biological Sciences, 279, 601-609.

Putz, D. A., Gaulin, S. J. C., Sporter, R. J., \& McBurney, D. H. (2004). Sex hormones and finger length: what does 2D:4D indicate? Evolution and Human Behavior, 25, 182-199.

Ridgeway, C. L. (2006). Gender as an organizing force in social relations: implications for the future of inequality. In F. D. Blau, M. C. Brinton, \& D. B. Grusky (Eds.), The declining significance of gender (pp. 265-287). New York: Russell Sage.

Rose, M. R., \& Oakley, T. H. (2007). The new biology: beyond the modern synthesis. Biology Direct, 2, 30-47.

Ryan, M. J., \& Rand, A. S. (1993). Sexual selection and signal evolution: the ghost of biases past. Philosophical Translations of the Royal Society of London, B, 340, 187-195.

Sanderson, S. K., \& Ellis, L. (1992). Theoretical and political perspectives of American sociologists in the 1990s. The American Sociologist, 23, 26-42.

Schmitt, D. P. (2003). Universal sex differences in the desire for sexual variety: tests from 52 nations, 6 continents, and 13 islands. Journal of Personality and Social Psychology, 85(1), 85-104.

Schmitt, D. P., \& Pilcher, J. J. (2004). Evaluating evidence of psychological adaptation: how do we know one when we see one? Psychological Science, 15, 643-649.

Schulz, K. M., Molenda-Figueira, H. A., \& Sisk, C. L. (2009). Back to the future: the organizational-activational hypothesis adapted to puberty and adolescence. Hormones and Behavior, 55, 597-604.

Seeman, E., Hopper, J. L., Young, N. R., Formica, C., Goss, P., \& Tsalamandris, C. (1996). Do genetic factors explain associations between muscle strength, lean mass, and bone density? A twin study. American Journal of Physiology, 270, E320-E327.

Shackelford, T. K., Schmitt, D. P., \& Buss, D. M. (2005). Universal dimensions of human mate preferences. Personality and Individual Differences, 39, 447-458.

Simon, H. A. (1980). The behavioral and social sciences. Science, 209, $72-78$.

Simonton, D. K. (2008). Scientific talent, training, and performance: intellect, personality, and genetic endowment. Review of General Psychology, 12, 28-46.

Sinervo, B., Miles, D. B., Frankino, W. A., Klukowski, M., \& DeNardo, D. F. (2000). Testosterone, endurance, and Darwinian fitness: natural and sexual selection on the physiological bases of alternative male behaviors in side-blotched lizards. Hormones and Behavior, $38,222-233$. 
Singh, D. (1993). Adaptive significance of waist-to-hip ratio and female physical attractiveness. Journal of Personality and Social Psychology, 65, 293-307.

Sprecher, S., Sullivan, Q., \& Hatfield, E. (1994). Mate selection preferences: gender differences examined in a national sample. Journal of Personality and Social Psychology, 66, 1074-1080.

Swerdloff, R. S., Wang, C., Hines, M., \& Gorski, R. (1992). Effect of androgens on the brain and other organs during development and aging. Psychoneuroendocrinology, 17, 375-383.

Talarovičová, A., Kršková, L., \& Blažeková, J. (2009). Testosterone enhancement during pregnancy influences the 2D: 4D ratio and open field motor activity of rat siblings in adulthood. Hormones and Behavior, 55, 235-239.

Tappé, M., Bensman, L., Hayashi, K., \& Hatfield, E. (2013). Gender differences in receptivity to sexual offers: a new research prototype. Interpersonal: An International Journal on Personal Relationships, 7, 323-344.

Temfemo, A., Hugues, J., Chardon, K., Mandengue, S.-H., \& Ahmaidi, S. (2009). Relationship between vertical jumping performance and anthropometric characteristics during growth in boys and girls. European Journal of Pediatrics, 168, 457-464.

Thomas, J. R., \& French, K. E. (1985). Gender differences across age in motor performance: a meta-analysis. Psychological Bulletin, 98, 260-282.

Thor, D. H., \& Holloway, W. R. (1985). Play soliciting behavior in prepubertal and postpubertal male rats. Animal Learning \& Behavior, $13,327-330$.

Toga, A. W., \& Thompson, P. M. (2005). Genetics of brain structure and intelligence. Annual Review in Neuroscience, 28, 1-23.

Townsend, J. M., Kline, J., \& Wasserman, T. H. (1995). Low-investment copulation: sex differences in motivation and emotional reactions. Ethology and Sociobiology, 16, 25-51.

Travis, C. B. (2003). Talking evolution and selling difference. In C. B. Travis (Ed.), Evolution, gender, and rape (pp. 3-27). Cambridge, MA: MIT Press.

Trivers, R. L. (1972). Parental investment and sexual selection. In B. Campbell (Ed.), Sexual selection and the descent of man 18711971 (pp. 136-179). Chicago: Aldine.

Trivers, R., Manning, J., \& Jacobson, A. (2006). A longitudinal study of digit ratio (2D:4D) and other finger ratios in Jamaican children. Hormones and Behavior, 49, 150-156.
Udry, J. R. (1994). The nature of gender. Demography, 31, 561-573.

van Anders, S. M., Vernon, P. A., \& Wilbur, C. J. (2006). Finger-length ratios show evidence of prenatal hormone-transfer between opposite-sex twins. Hormones and Behavior, 49, 315-319.

Van Praagh, E., Fellmann, N., Bedu, M., Falgairette, G., \& Coudert, J. (1990). Gender difference in the relationship of anaerobic power output to body composition in children. Pediatric Exercise Science, 2, 336-348.

Vergne, J. P., \& Durand, R. (2010). The missing link between the theory and empirics of path dependence: conceptual clarification, testability issue, and methodological implications. Journal of Management Studies, 47, 736-759.

Vitzthum, V. J., Worthman, C. M., Beall, C. M., Thornburg, J., Vargas, E., Villena, M., \& Spielvogel, H. (2009). Seasonal and circadian variation in salivary testosterone in rural Bolivian men. American Journal of Human Biology, 21, 762-768.

Voracek, M., Dressler, S. G., \& Manning, J. T. (2007). Evidence for assortative mating on digit ratio (2D:4D), a biomarker for prenatal androgen exposure. Journal of Biosocial Science, 39, 599-612.

Waynforth, D., \& Dunbar, R. I. M. (1995). Conditional mate choice in humans: evidence from lonely hearts advertisements. Behaviour, 132, 735-739.

Wiederman, M. W. (1993). Evolved gender differences in mate preferences: evidence from personal advertisements. Ethology and Sociobiology, 14, 331-351.

Wiley, R. H., \& Poston, J. (1996). Indirect mate choice, competition for mates and coevolution of the sexes. Evolution, 50, 1371-1381.

Williams, T. J., Pepitone, M. E., Christensen, S. E., Cooke, B. M., Huberman, A. D., Breedlove, N. J., et al. (2000). Finger-length ratios and sexual orientation. Nature, 404, 455-456.

Williams, M. J., Paluck, E. L., \& Spencer-Rodgers, J. (2010). The masculinity of money: automatic stereotypes predict gender differences in estimated salaries. Psychology of Women Quarterly, 34(1), 7-20.

Woodhouse, L. J., Reisz-Porszasz, S., Javanbakht, M., Storer, T. W., Lee, M., Zerounian, H., \& Bhasin, S. (2003). Development of models to predict anabolic response to testosterone administration in healthy young men. American Journal of Physiology, Endocrinology and Metabolism, 284, E1009-E1017.

Zheng, Z., \& Cohn, M. J. (2011). Developmental basis of sexually dimorphic digit ratios. Proceedings of the National Academy of Sciences, 108, 16289-16294. 